\title{
Flexural performance of innovative hybrid sandwich panels with special focus on the shear connection behavior
}

\author{
M. Mastali ${ }^{1 *}$, I. B. Valente ${ }^{2}$, Joaquim A. O. Barros ${ }^{3}$
}

1. ISISE, Dep. Civil Eng., School Eng., University of Minho Campus de Azurém 4800-058 Guimarães, Portugal.

Corresponding author Email*: m.mastali@civil.uminho.pt

Mobile*: $+351-915427040$

2. Assistant Professor, Minho University, Department of Civil Engineering, Campus de Azurém, 4800-058 Guimarães, Portugal.

3. Full Professor, Minho University, Department of Civil Engineering, Campus de Azurém, 4800-058 Guimarães, Portugal.

\begin{abstract}
The present study intends to evaluate the flexural performance of hybrid sandwich panels through the execution of four point bending tests. The proposed hybrid sandwich panel uses Deflection Hardening Cementitious Composites (DHCC) on the top layer, a GFRP bottom layer and perforated shear connectors in the GFRP ribs to transfer shear stresses between top and bottom layers.

The tested hybrid slabs use two types of shear connectors, which include indented and perforated shapes. The tests were performed to study the behavior of a novel shear connection between the GFRP ribs and the DHCC layer that is here proposed. A comparison on the obtained experimental results was executed to clarify the influence of the shear connectors' geometries on the flexural performance of the developed hybrid slabs.

The results show that the shear connection mechanical behavior strongly influences the peak load, the deflection at peak load, the post-peak load carrying capacity and the degree of composite action of the hybrid slabs.
\end{abstract}

Key words: Hybrid sandwich panel; Deflection Hardening Cement Composites (DHCC); GFRP perforated shear connectors; GFRP indented shear connectors; Flexural loading.

Mastali, Mohammad, Valente, Isabel B., Barros, Joaquim A. O. (2017).

Flexural performance of innovative hybrid sandwich panels with special focus on the shear connection behaviour.

Paper submitted to Composite Structures, Elsevier, ISSN 0263-8223. 


\section{Introduction}

Sandwich panels are an interesting solution for building floors due to their high strength to weight ratio and adequate levels of acoustic and thermal insulation. Low self-weight, and high stiffness and durability have increased the demand for this type of composite structures, and several studies have been dedicated to improve the structural performance of sandwich panels. Typical sandwich panels are composed of three different layers that include two thin, stiff and resistant composite material skins, such as fiber reinforced polymer (FRP) materials, separated by a layer of a low density material that is usually made with polyvinyl chloride (PVC), Basalt, polystyrene (PS), polyurethane (PU), polymethacrylamide, polyetherimide (PEI) or styreneacrylonitrile (SAN). The proper combination of different core and skin materials may promote the merge of the most advantageous properties of each constituent material, and even eliminate some negative characteristics. The combination of skins with appropriate cores leads to a structural response characterized by high stiffness-to-weight and high strength-to-weight ratios. The development of new production techniques has made sandwich panels more cost-competitive, with especial precautions for attributing to these panels requisites for an easy and fast mounting [1].

The main deficiencies that have been reported to this type of sandwich panels are: its low load carrying capacity when compared to the one of structural elements constituted by traditional materials, like concrete and steel; low resistance to high temperatures; susceptibility to the occurrence of local and global failure modes. These concerns create extra difficulties for the designers, with a detrimental consequence on the acceptance of sandwich panels by the construction industry [1]. Therefore, several studies have been carried out to overcome the indicated disadvantages, not only by using new composite materials, but also disposing the materials according to new structural configurations that optimize the potential of each constituent.

Norton [2] proposed a deck solution that consists of two skins (E-glass fabric) and trussed GFRP webs to act as flexural members supported by the girders. Each skin includes two orthogonal woven fabrics stitched together by fibers in the perpendicular directions $\left(0^{\circ}\right.$ and $\left.90^{\circ}\right)$ to form a 3D GFRP material for the entire cross section. Balsa cores are adopted to maintain the configuration of the cross section during the vacuum infusion process with epoxy resin. As indicated in Fig. 1a, the top skin is a concrete layer, thereby a hybrid sandwich panel was proposed. As shown in Fig. 1e and Fig. 1f, both steel and composite shear connectors are used in an attempt of ensuring the composite action between the GFRP cross section and the top concrete layer [2].

Mastali, Mohammad, Valente, Isabel B., Barros, Joaquim A. O. (2017).

Flexural performance of innovative hybrid sandwich panels with special focus on the shear connection behaviour.

Paper submitted to Composite Structures, Elsevier, ISSN 0263-8223. 
The metallic shear connectors showed good performance, but were difficult to work with beneath the vacuum bag, during the infusion process. This difficulty derived from puncture of the vacuum bag caused by the metallic shear connectors. As shown in Figs 1b, 1c and 1d, the composite shear connectors were simpler to infuse and maintain their bond with the composite deck. However, the bond between the concrete and the top GFRP skin of the hybrid panels was inadequate for high loading levels, and debonding was the common failure mode. This study illustrated that the shear connection between the concrete layer and the composite surface is the limiting factor for the ultimate load carrying capacity of the tested elements.

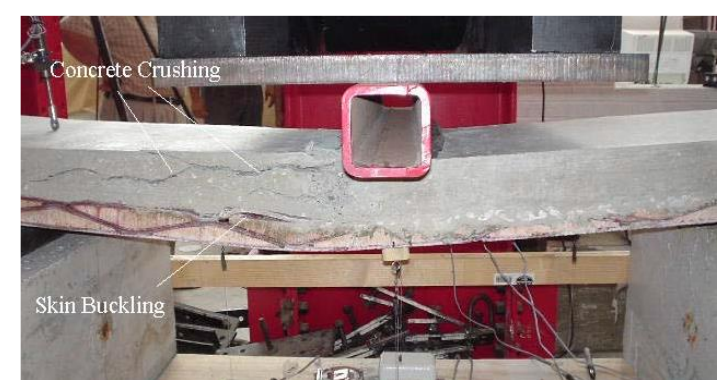

a)

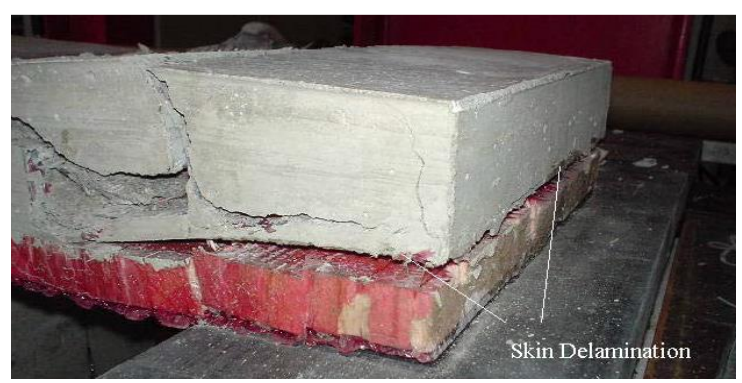

b)

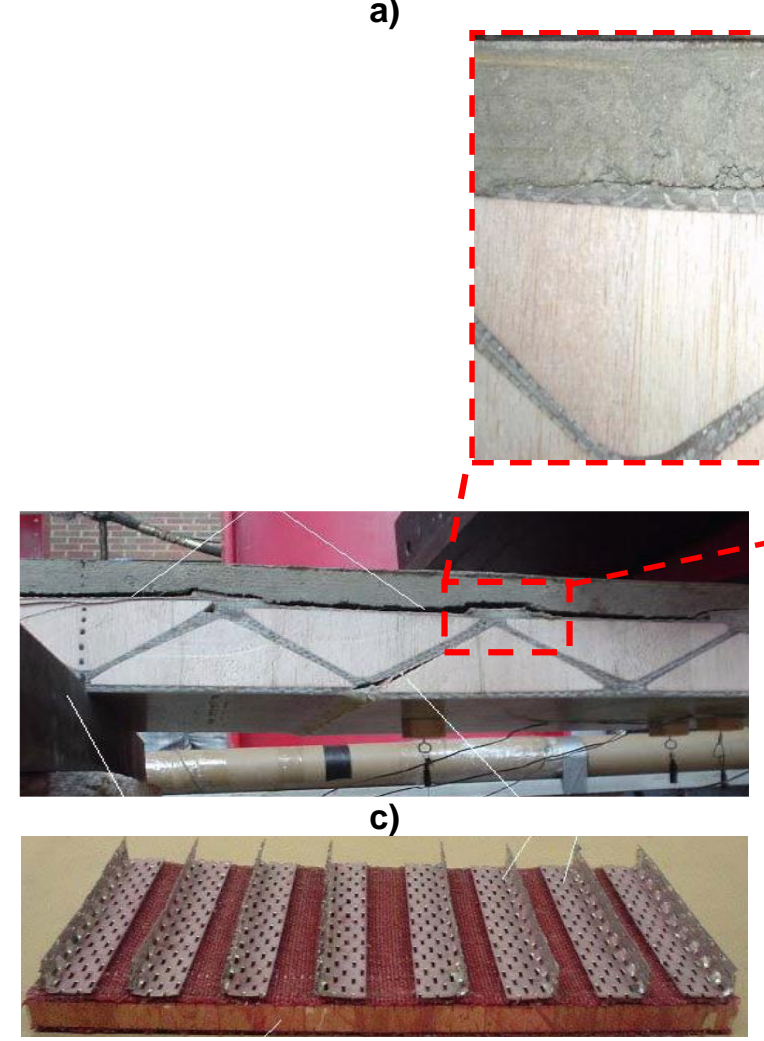

e)

\section{Inadequate}

bond between

GFRP and concrete

Fig 1. a) Concrete crushing and shearing; b) concrete shearing; c) concrete delamination; d) concrete delamination and shear; e) steel shear connectors; f) composite shear connectors [2]

Mastali, Mohammad, Valente, Isabel B., Barros, Joaquim A. O. (2017).

Flexural performance of innovative hybrid sandwich panels with special focus on the shear connection behaviour.

Paper submitted to Composite Structures, Elsevier, ISSN 0263-8223. 
In 2013, Mastali et al. [3] used FEM-based analysis to perform a parametric study on hybrid sandwich panels with GFRP bottom skin and ribs, while the top skin was made of deflection hardening fiber-reinforced cementitious composite (DHCCs). This FEM based study was executed to optimize the slab dimensions and reveal the contribution of each structural component to the global behavior of the hybrid sandwich slabs. The authors found out that hybrid sandwich slabs present high load carrying capacity, high span-to-weight ratio and high stiffness [3]. Previous experimental studies on hybrid sandwich panels, presented in [2, 4], showed that there are some difficulties in transferring shear stresses from top skin to bottom skin through shear connectors.

In the present study, efforts are made to assess the flexural performance of hybrid sandwich panels with the execution of four point bending tests. These bending tests aim to analyze the behavior of shear connectors that are part of the GFRP ribs, and stay embedded in the DHCC layer after curing. Two types of shear connectors are used in the tested hybrid slabs: indented and perforated shear connectors.

Therefore, two hybrid slabs with indented shear connectors are manufactured and tested under Four Point Bending (FPB) test. In [5], two other hybrid slabs with perforated shear connectors were previously tested under FPB test configuration, and the corresponding experimental results are herein used to execute a comparative analysis.

\section{Experimental Program}

\subsection{Dimensions of slab's components}

Two optimized hybrid sandwich slabs with total thickness of $140 \mathrm{~mm}$ and $172 \mathrm{~mm}$ were proposed in [3], which are depicted in Fig. 2a. The dimensions of slab's components were obtained with a parametric FEM-based analysis, described elsewhere [3]. Table 1 lists the geometry of the components of the two types of sandwich slabs developed, herein designated by Slab 1 and Slab 2, with total thickness of $172 \mathrm{~mm}$ and $140 \mathrm{~mm}$, respectively. Each array of properties corresponds to a column in Table 1, where the meaning of the letters is represented in Fig. $2 \mathrm{~b}$.

Mastali, Mohammad, Valente, Isabel B., Barros, Joaquim A. O. (2017).

Flexural performance of innovative hybrid sandwich panels with special focus on the shear connection behaviour.

Paper submitted to Composite Structures, Elsevier, ISSN 0263-8223. 


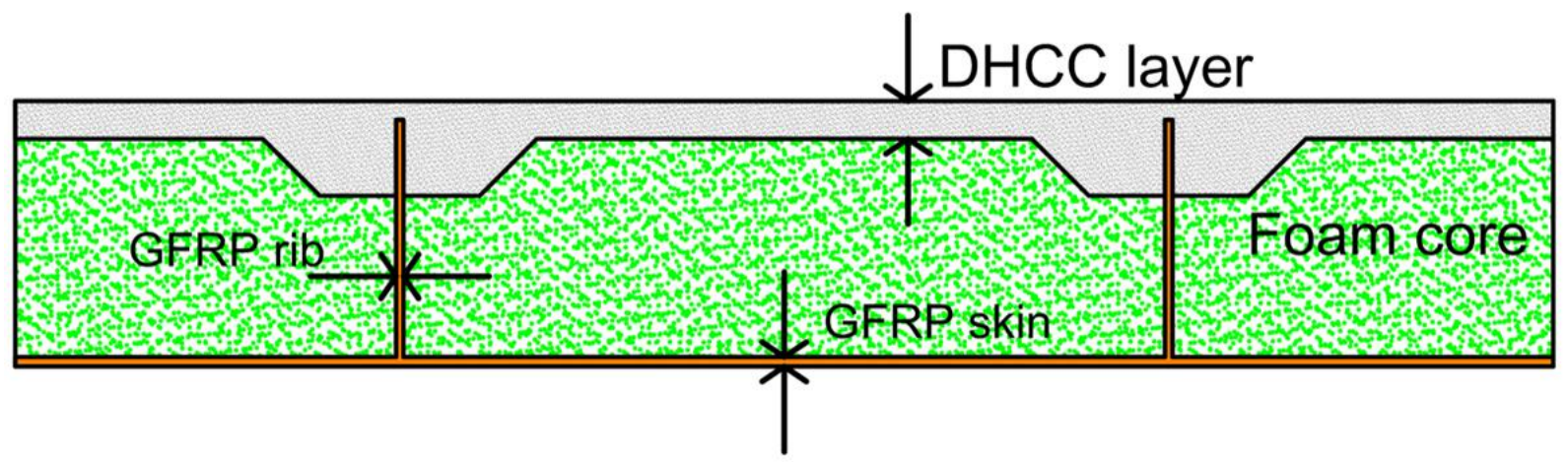

a)

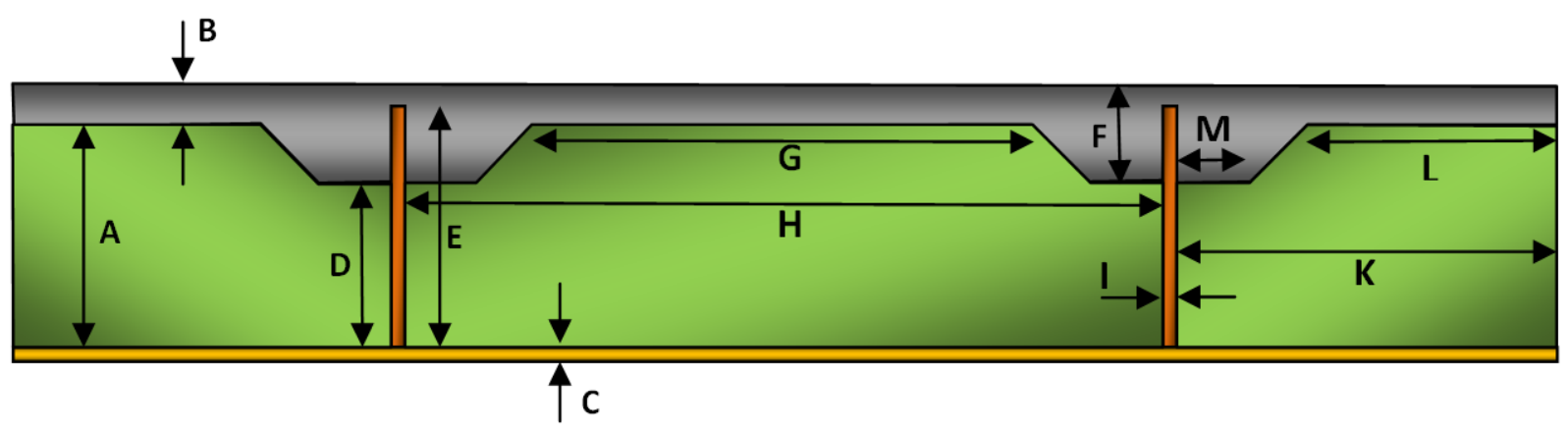

b)

Fig 2. Proposed hybrid sandwich slabs: a) components; b) geometric characterization

Table 1. Geometric properties of the proposed slabs

\begin{tabular}{ccc}
\hline Name & Type 1 & Type 2 \\
\hline A & 149 & 115 \\
\hline B & 20 & 20 \\
\hline C & 3 & 5 \\
\hline D & 119 & 85 \\
\hline E & 160 & 130 \\
\hline F & 50 & 50 \\
\hline G & 260 & 260 \\
\hline H & 400 & 400 \\
\hline I & 6 & 4 \\
\hline K & 200 & 200 \\
\hline $\mathbf{L}$ & 130 & 130 \\
\hline $\mathbf{M}$ & 40 & 40
\end{tabular}

Mastali, Mohammad, Valente, Isabel B., Barros, Joaquim A. O. (2017).

Flexural performance of innovative hybrid sandwich panels with special focus on the shear connection behaviour.

Paper submitted to Composite Structures, Elsevier, ISSN 0263-8223. 


\subsection{Material Properties}

The proposed hybrid sandwich slab comprises four components that include DHCC material as top layer, GFRP skin as bottom layer, GFRP rib to transfer shear stresses between DHCC layer to GFRP skin, and polyurethane foam core as insulation material, as shown in Fig. 2a. The mechanical properties of the materials used are presented in this section.

\subsubsection{Deflection Hardening Cement Composites (DHCC)}

Fiber Reinforced Cementitious Composites (FRCC) is a term commonly used for a broad class of materials. Every FRCC consists of two basic components: a cementitious-based material called matrix, which is reinforced by steel or synthetic relatively short fibers that are generally randomly distributed. The most widely accepted methodology to classify FRCCs is based on the type of stress-strain response obtained in direct tension test and load-deflection relationship determined in bending test. Some FRCCs are strain-softening in direct tension (the tensile stress decreases with the increase of tensile strain after crack initiation of the matrix), but in bending the flexural stress increases with the deflection after crack initiation of the matrix. These materials are called deflection-hardening FRCCs, and form the category of Deflection Hardening Cement Composites (DHCC) [21].

As indicated in Fig. 3, DHCC layer in the hybrid slab can be considered as a continuous shallow beam supported in the GFRP ribs. Due to the applied loads, there are negative and positive bending moments in the middle-supports (hogging regions) and in the mid-spans (sagging regions), respectively. The DHCC material offers high ductile behavior due to bridging action of fibers, which enables the formation of multiple cracks on the tensile surface (Fig. 3a). On the opposite, plain mortar presents brittle behavior by forming a unique crack due to its relatively low fracture energy, as shown in Fig. 3b. In previous research works on the subject of hybrid sandwich panels, plain mortar was used as top skin [2, 4], with a significant reduction of flexural capacity after crack initiation deflection $\left(D_{c r}\right)$. Due to the statically indeterminate character of the supporting conditions provided by the GFRP ribs to the top cementitious layer in the sandwich slab, the stress redistribution capacity of DHCC, due to the fiber reinforcement mechanisms, ensures a significant contribution in terms of load carrying capacity and ductility for this type of slabs.

Mastali, Mohammad, Valente, Isabel B., Barros, Joaquim A. O. (2017).

Flexural performance of innovative hybrid sandwich panels with special focus on the shear connection behaviour.

Paper submitted to Composite Structures, Elsevier, ISSN 0263-8223. 

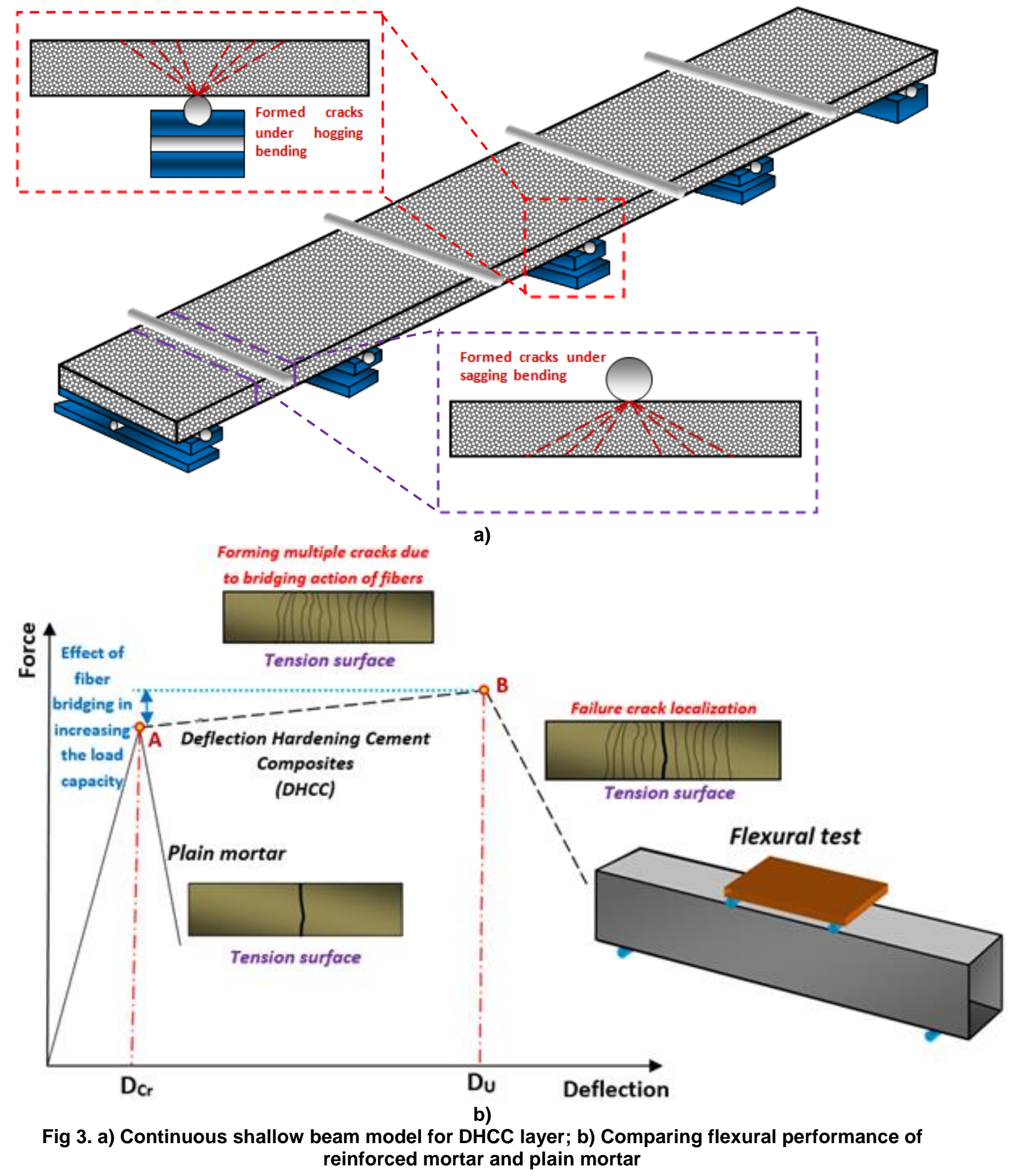

Mastali, Mohammad, Valente, Isabel B., Barros, Joaquim A. O. (2017).

Flexural performance of innovative hybrid sandwich panels with special focus on the shear connection behaviour.

Paper submitted to Composite Structures, Elsevier, ISSN 0263-8223. 
In previous works [6, 7], various deflection hardening materials were developed, but the novelty of the DHCC material herein proposed is the use of PAN fibers of different length, $6 \mathrm{~mm}$ and $12 \mathrm{~mm}$. The mechanical properties of PAN fibers used are listed in Table 2.

Table 2. Mechanical properties of short and long PAN fibers [14]

\begin{tabular}{lccccc}
\hline Fiber & $\begin{array}{c}\text { Length } \\
(\mathbf{m m})\end{array}$ & $\begin{array}{c}\text { Diameter } \\
(\boldsymbol{\mu m})\end{array}$ & $\begin{array}{c}\text { Young's } \\
\text { modulus } \\
(\mathbf{M P a})\end{array}$ & $\begin{array}{c}\text { Tensile } \\
\text { strength } \\
(\mathbf{M P a})\end{array}$ & $\begin{array}{c}\text { Density } \\
\left(\mathbf{g} / \mathbf{c m}^{\mathbf{3}}\right)\end{array}$ \\
\hline PAN 6 & 6 & 58 & 9910 & 564 & 1.17 \\
PAN 12 & 12 & 26 & 6856 & 264 & 1.17 \\
\hline
\end{tabular}

The components used in the composite mixtures include Portland cement type 42.5R, fly ash, limestone filler, sand, water, Viscosity Modification Agent (VMA) and superplasticizer. The developed mixture proportions are indicated in Table 3.

Table 3. Mixture proportions (in weight)

\begin{tabular}{ccccccc}
\hline $\begin{array}{c}\text { Cement/ } \\
\text { Powder }\end{array}$ & $\begin{array}{c}\text { Fly ash/ } \\
\text { Powder }\end{array}$ & $\begin{array}{c}\text { Limestone } \\
\text { filler/Powder }\end{array}$ & Sand/Powder & $\begin{array}{c}\text { Admixture } \\
\text { Powder }\end{array}$ & $\begin{array}{c}\text { Water/ } \\
\text { Powder }\end{array}$ & $\begin{array}{c}\text { Content of fibers (in } \\
\text { volume, \%) }\end{array}$ \\
\hline 0.456 & 0.456 & 0.087 & 0.183 & 0.030 & 0.354 & $(1 \%$ PAN 6, 3\% PAN 12) \\
\hline
\end{tabular}

* Powder: Cement + Fly ash

** Admixture: Viscosity modification agent (VMA) + Superplasticizer

Flexural, compressive, and tensile properties of DHCC material were evaluated with a set of flexural, compression and tensile tests. Three prismatic beams with dimensions of $245 \times 60 \times 40 \mathrm{~mm}^{3}$ were cast and tested in Three Point Bending (TPB) and Four Point Bending (FPB) test configurations for the characterization of the flexural properties of DHCC. The loading was applied in displacement control by imposing a displacement rate of $0.6 \mathrm{~mm} / \mathrm{min}$ in a Linear Variable Differential Transformer (LVDT) attached to the actuator.

In the present study, the deflection hardening level of the developed DHCC was evaluated with the ductility index defined in equation (1):

$$
\mu=\frac{D_{U}}{D_{c r}}
$$

where $D_{c r}$ and $D_{U}$ are the deflection at crack initiation of the matrix (corresponding to the end of the first linear branch - Point A in Fig. 3) and to the maximum flexural capacity after crack initiation (Point B in Fig. 3), respectively.

Mastali, Mohammad, Valente, Isabel B., Barros, Joaquim A. O. (2017).

Flexural performance of innovative hybrid sandwich panels with special focus on the shear connection behaviour.

Paper submitted to Composite Structures, Elsevier, ISSN 0263-8223. 
The flexural properties of DHCC material obtained in the experimental tests are listed in Table 4. According to the obtained results, DHCC material presents a high-ductile deformation capacity with flexural strength of $10.70 \mathrm{MPa}$ and a ductility index that is always higher than 8.2. This flexural strength is achieved through the development of multiple cracks on the tensile surfaces of the beams. These multiple cracks are caused by the PAN fibers reinforcement mechanisms that ensured a flexural strength higher than the flexural stress at crack initiation of about $75 \%$ and 85\% under TPB and FPB tests, respectively.

Table 4. Flexural properties of DHCC material

\begin{tabular}{cccccc}
\hline $\begin{array}{c}\text { Test } \\
\text { type }\end{array}$ & $\begin{array}{r}\text { Flexural stress at crack } \\
\text { initiation/corresponding } \\
\text { deflection } \\
(\mathrm{MPa} / \mathrm{mm})\end{array}$ & $\begin{array}{c}\text { Flexural strength / corresponding } \\
\text { deflection }\end{array}$ & Ductility index \\
& Average & SD & \multicolumn{2}{c}{$(\mathrm{MPa} / \mathrm{mm})$} & $(\mu)$ \\
\hline TPB & $6.22 / 0.05$ & $0.74 / 0.04$ & Average & SD & \\
FPB & $5.73 / 0.07$ & $0.06 / 0.01$ & $10.72 / 0.32$ & $1.89 / 0.06$ & 8.25 \\
\hline
\end{tabular}

Fig. 4a depicts the set up adopted for characterizing the direct tensile behavior of the DHCC. Three prismatic specimens of $250 \times 80 \times 18 \mathrm{~mm}^{3}$ were used for the direct tensile tests. These specimens were cut from a larger panel, with dimensions of $500 \times 500 \times 20 \mathrm{~mm}^{3}$. Loading was applied in displacement control by adopting a displacement rate of $0.18 \mathrm{~mm} / \mathrm{min}$ in an LVDT installed in the actuator. The results obtained from averaging three specimens in the tensile tests are presented in Fig. 4b and they indicate that there is small pseudo-strain hardening behavior in the specimens. After initiation of the first crack, at a tensile stress of $2.06 \mathrm{MPa}$ and strain of $0.12 \%$, specimens exhibited a small hardening branch due to the formation of other cracks up to a tensile strength of $2.42 \mathrm{MPa}$, which occurred for a tensile strain of $0.22 \%$. The specimen has then entered in a softening response, and when the test has ended it has supporting a tensile stress of 1.17 MPa at a tensile strain of $0.71 \%$.

Mastali, Mohammad, Valente, Isabel B., Barros, Joaquim A. O. (2017).

Flexural performance of innovative hybrid sandwich panels with special focus on the shear connection behaviour.

Paper submitted to Composite Structures, Elsevier, ISSN 0263-8223. 


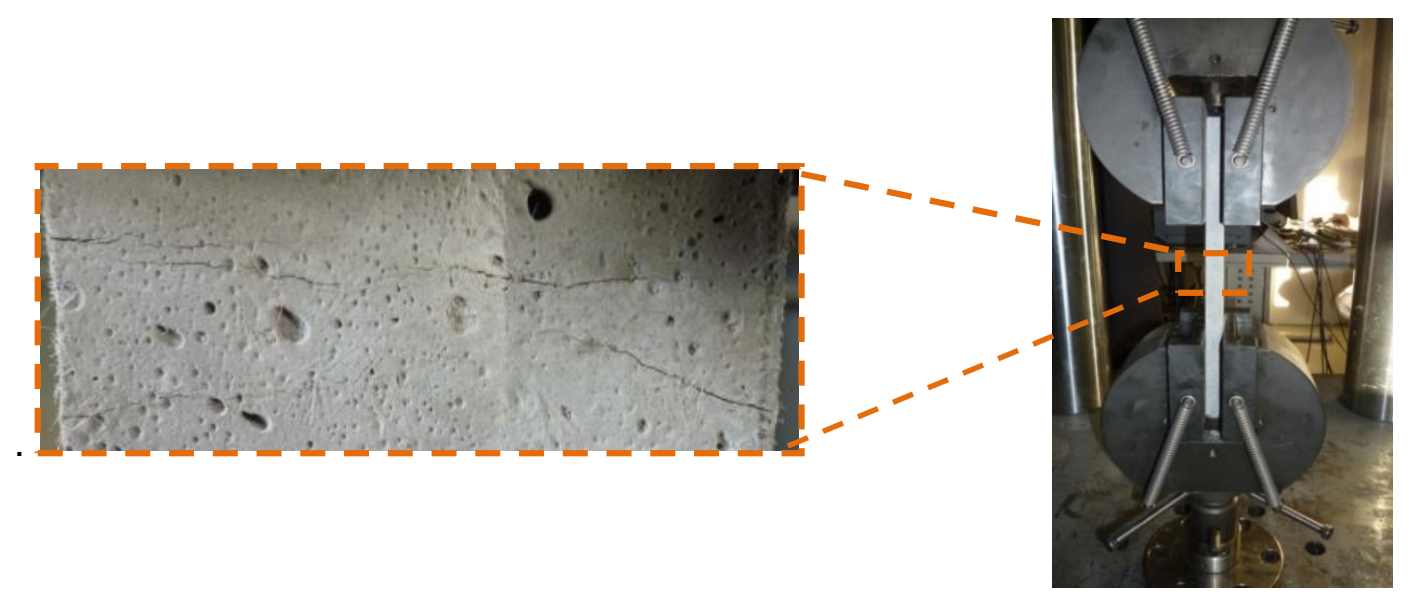

a)

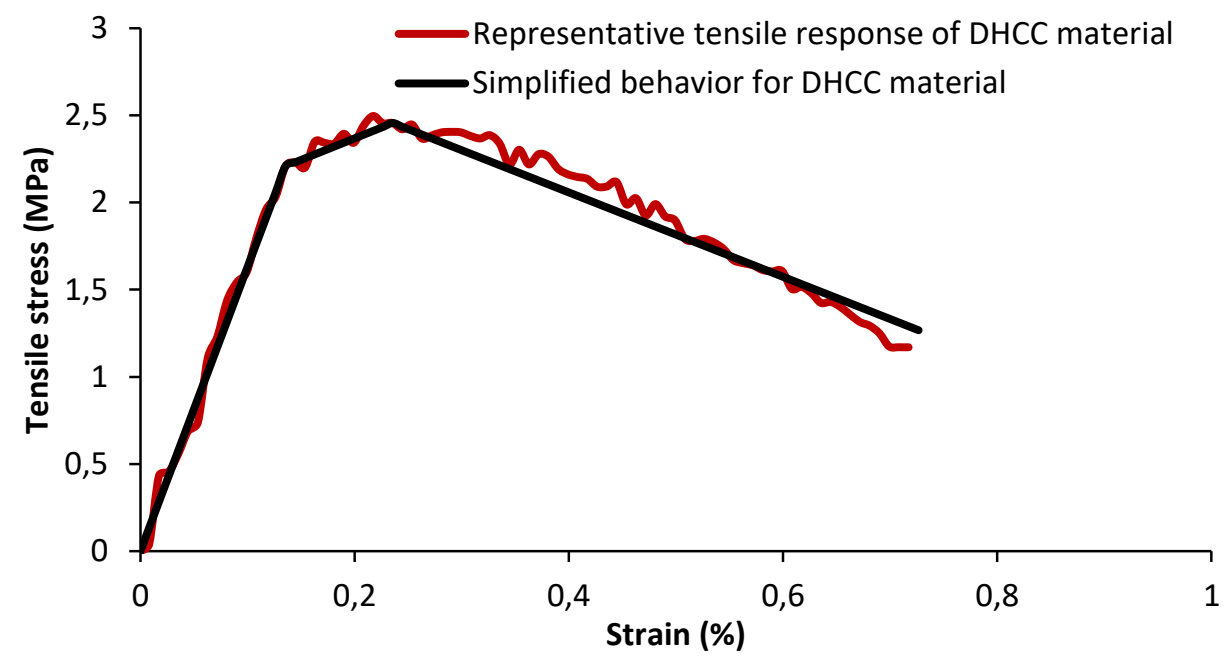

b)

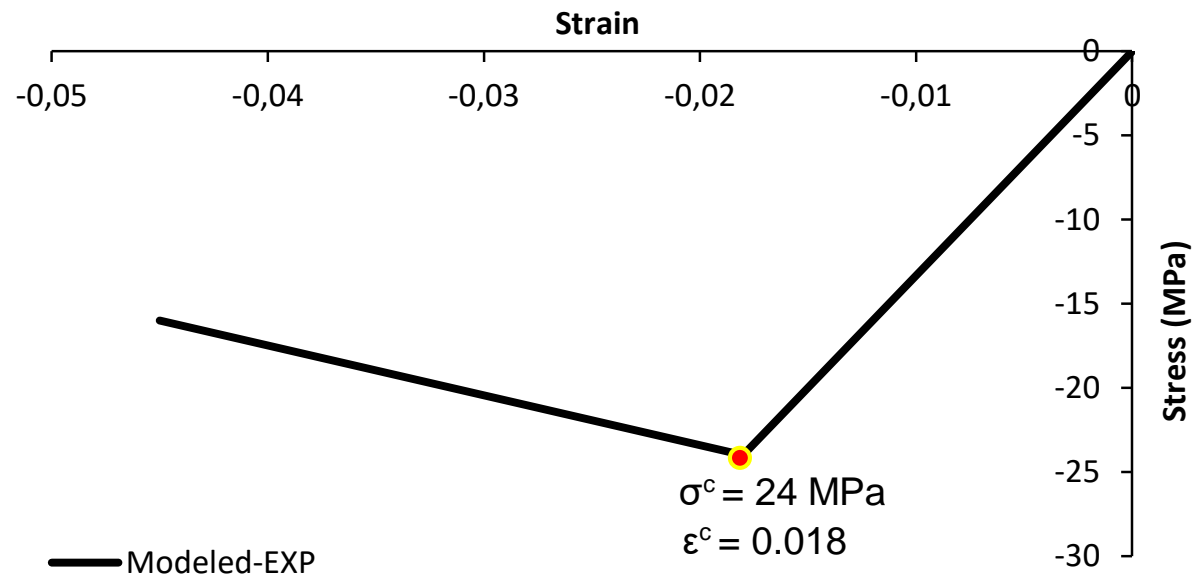

c)

Fig 4. Direct tensile tests with DHCC specimens: a) adopted test setup; b) typical stress vs. strain response; c) stress vs. strain for DHCC layer in compression

Mastali, Mohammad, Valente, Isabel B., Barros, Joaquim A. O. (2017).

Flexural performance of innovative hybrid sandwich panels with special focus on the shear connection behaviour.

Paper submitted to Composite Structures, Elsevier, ISSN 0263-8223. 
Cylinder specimens of $100 \mathrm{~mm}$ diameter and $200 \mathrm{~mm}$ height were cast to assess the uniaxial compressive behavior of DHCC, by adopting the ASTM C39 recommendations [18]. Compressive load was applied to these specimens by displacement control at a displacement rate of $0.12 \mathrm{~mm} / \mathrm{min}$. An average compressive strength of $20.37 \mathrm{MPa}$ and a Young's modulus of $9.67 \mathrm{GPa}$, with a standard deviation of $1.51 \mathrm{MPa}$ and $0.20 \mathrm{GPa}$, respectively, was obtained at 40 days of age for the DHCC.

It is worth stating that the density of the developed DHCC was $18.0 \mathrm{kN} / \mathrm{m}^{3}$, being $25 \%$ lighter than normal density concrete (density of about $24 \mathrm{kN} / \mathrm{m}^{3}$ ). More details on properties and fabrication of the developed DHCC material can be found in [5].

The authors are aware that the results obtained with the standard beam specimens for thin elements are questionable, because the fiber dispersion and orientation are strongly affected by the element's geometry [19]. Additionally, due to the geometry of DHCC layer, the fiber distribution tends to be predominantly parallel to layer's plane, while in the standard beams the fibers have an almost 3D random distribution character. Even so, the obtained results can provide opportune information about the flexural behavior of the DHCC in the ribbed zones of the sandwich slab, where, due to the largest thickness and presence of the GFRP rib, the fibers may have a fiber distribution and orientation not too different to the tested beam specimens.

Considering the cross section adopted for the DHCC layer, already presented in section 2.1, it was considered important to have a deeper understanding on the flexural performance of the cross section chosen for DHCC layer. As shown in Fig. 5a, three prismatic beams were cut from the DHCC layer of the hybrid slab along the longitudinal and transversal orientations. It is worth stating that three specimens were cut at each direction. The specimens presented rectangular and trapezoidal cross sections, as presented in Fig. 5, and were experimentally tested under flexural loading.

The cross section of both the longitudinal and transversal extracted prismatic beams has a width and a thickness of the $20 \mathrm{~mm}$ and $80 \mathrm{~mm}$, respectively, while the span length of the longitudinal and transversal beams was $250 \mathrm{~mm}$ and $400 \mathrm{~mm}$, respectively. The cross section of the trapezoidal beams is indicated in Fig. $5 \mathrm{a}$ and Fig. $5 \mathrm{~d}$. The test setup adopted for the execution of FPB test is presented in Fig. $5 \mathrm{~b}$ and Fig. $5 \mathrm{c}$. The beams were loaded with a displacement rate of $0.6 \mathrm{~mm} / \mathrm{min}$. The load was recorded using a load cell with $10 \mathrm{kN}$ maximum capacity, and the deflection was measured with a LVDT of $10 \mathrm{~mm}$ stroke. Displacements were registered at the mid-span of the beams.

Mastali, Mohammad, Valente, Isabel B., Barros, Joaquim A. O. (2017).

Flexural performance of innovative hybrid sandwich panels with special focus on the shear connection behaviour.

Paper submitted to Composite Structures, Elsevier, ISSN 0263-8223. 


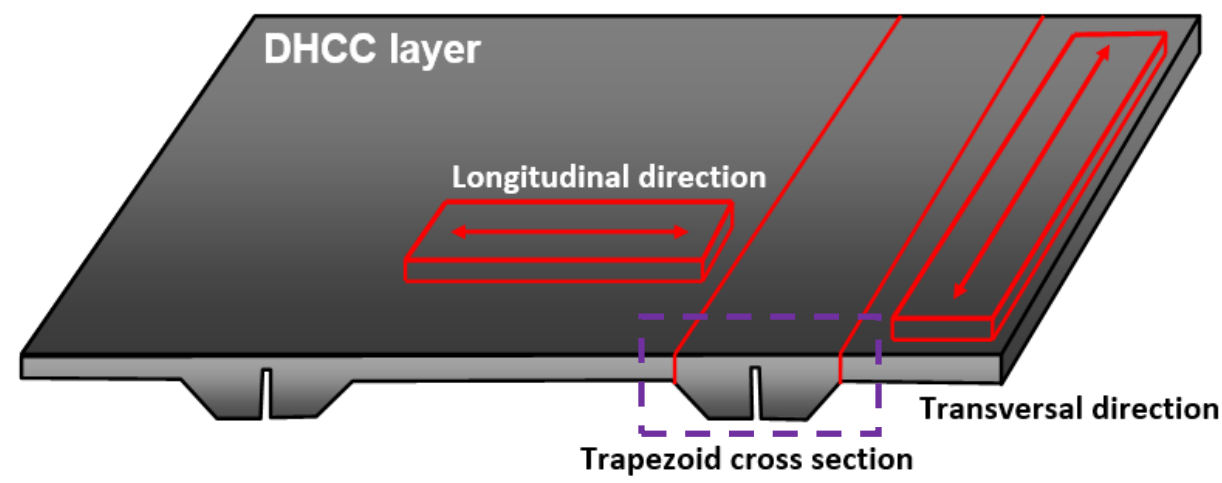

a) DHCC layer and schematic representation of extracted beams

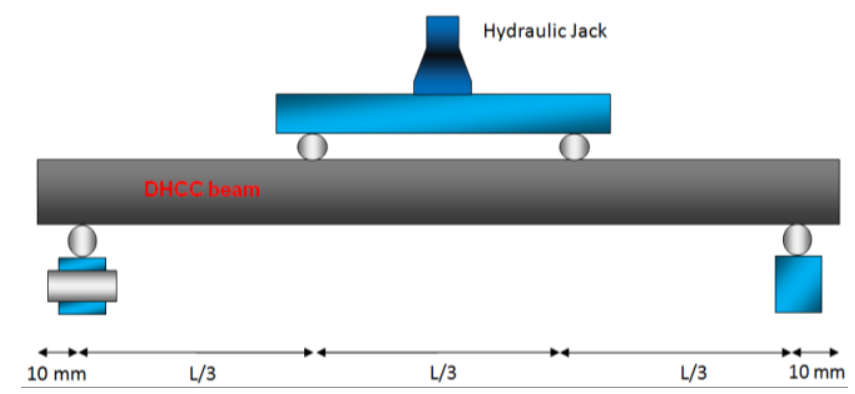

b) Test setup for FPB test on DHCC beams

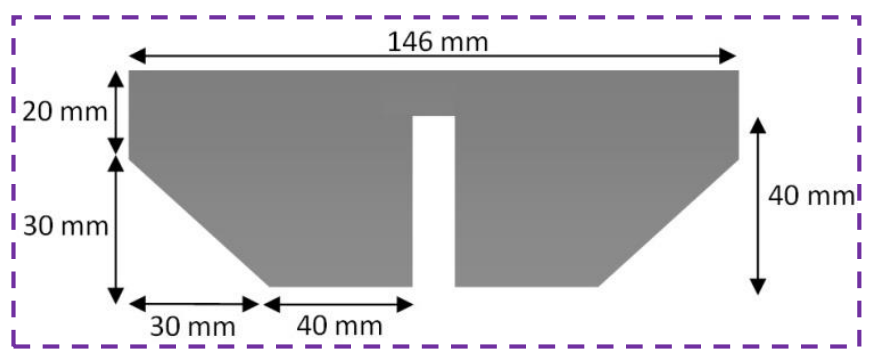

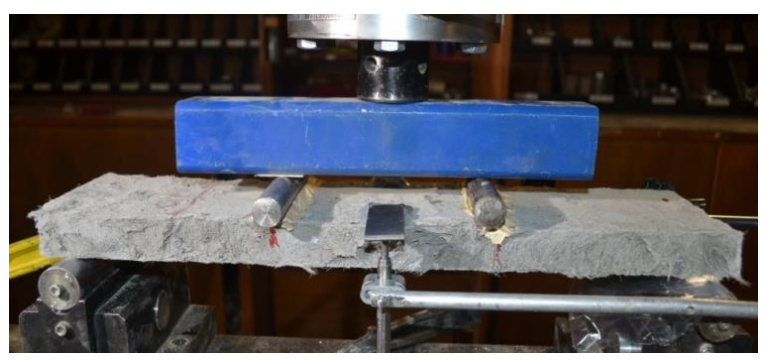

c) Bending test on transversal beam

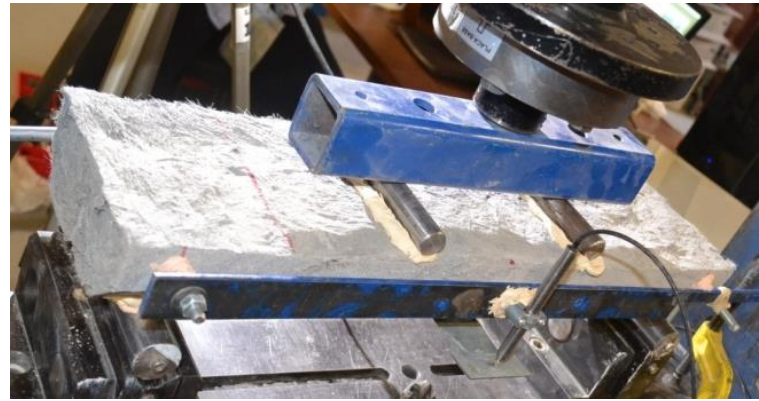

d) Bending test on trapezoidal beam

Fig 5. Beams extracted from DHCC layer and corresponding bending tests

The results obtained in the experimental assessment are depicted in Fig. 6 and listed in Table 5. The flexural stress of the beams was computed based on the given equation:

$$
\sigma=\frac{M y}{I}
$$

where $M$ is the bending moment, $I$ is the centroidal moment of inertia, and $Y$ is the distance from the neutral axis to the outermost edge. The authors used the presented Bernoulli formula to calculate the flexural stress of the beams. If the same calculation is to be done in the hybrid slabs, the influence of shear interaction stiffness on the elastic behaviour should be considered [22]. Mastali, Mohammad, Valente, Isabel B., Barros, Joaquim A. O. (2017).

Flexural performance of innovative hybrid sandwich panels with special focus on the shear connection behaviour.

Paper submitted to Composite Structures, Elsevier, ISSN 0263-8223. 
With respect to the results listed in Table 5, different ductility and flexural performance was obtained in the extracted beams.

In Fig. 6, ending the linear behavior and entering a hardening or softening behavior was defined as the criterion for determining the flexural stress at crack initiation.

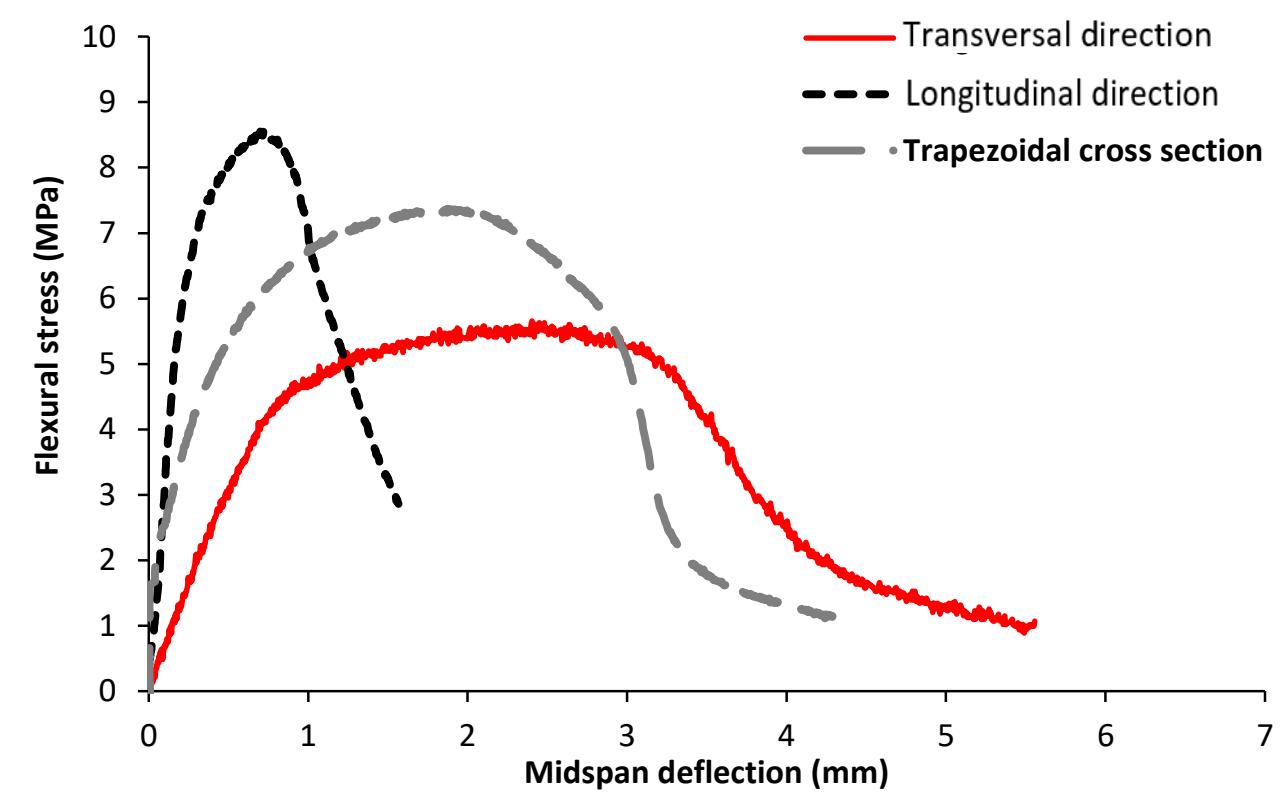

Fig 6. Flexural stress vs. mid-span deflection responses of extracted beams

A maximum flexural strength of $8.54 \mathrm{MPa}$ and a minimum ductility index of 2.30 were recorded for beams extracted in longitudinal direction. Differences in the obtained results are may be due to differences in cross sections and lengths of beams, once the fibre dispersion and orientation is strongly affected by the casting procedure and the elements geometry.

Table 5. Recorded results of flexural response from extracted beams

\begin{tabular}{cccc}
\hline Specimens & $\begin{array}{c}\text { Flexural stress at } \\
\text { crack initiation / } \\
\text { corresponding } \\
\text { deflection } \\
(\mathbf{M P a} / \mathbf{m m})\end{array}$ & $\begin{array}{c}\text { Flexural } \\
\text { strength / } \\
\text { corresponding } \\
\text { deflection } \\
(\mathbf{M P a} / \mathbf{m m})\end{array}$ & $\begin{array}{c}\text { Ductility } \\
\text { index }(\boldsymbol{\mu})\end{array}$ \\
\hline Longitudinal direction & $6.98 / 0.28$ & $8.54 / 0.69$ & 2.30 \\
Transversal direction & $4.26 / 0.86$ & $5.52 / 2.70$ & 3.55 \\
Trapezoidal cross section & $2.47 / 0.10$ & $7.30 / 2.06$ & 25.75 \\
\hline
\end{tabular}

Mastali, Mohammad, Valente, Isabel B., Barros, Joaquim A. O. (2017).

Flexural performance of innovative hybrid sandwich panels with special focus on the shear connection behaviour.

Paper submitted to Composite Structures, Elsevier, ISSN 0263-8223. 


\subsubsection{GFRP ribs and skin}

GFRP skin and ribs were fabricated with specific distribution of E-glass fibers and Distitron $3501 S 1$ resin type. For the bottom GFRP skin, a higher percentage of fibers was oriented at $0^{\circ}$ and a smaller percentage was oriented at 90․ In GFRP ribs, fibers are oriented in three directions, $0^{\circ}, 90^{\circ}$, and $45^{\circ}$, and a high percentage is aligned at $\pm 45^{\circ}$. The distribution of fibers in GFRP ribs and skins is detailed in Table 6. Based on ASTM D3039/D 3039M-00 recommendations, three GFRP skin coupons were prepared in each longitudinal and transverse direction in order to evaluate the modulus of elasticity, the ultimate tensile strength and the ultimate tensile strain [8]. The coupon's dimensions were $250 \times 25 \mathrm{~mm}^{2}$. Additionally, the same procedure was applied to prepare nine GFRP rib coupons in three fiber oriented directions $\left(0^{\circ}\right.$, $90^{\circ}$ and $45^{\circ}$ ). Tensile loading was applied to the GFRP coupons with a displacement rate of $2 \mathrm{~mm} / \mathrm{min}$. The obtained mechanical properties are also listed in Table 6.

Based on the results presented in Table 6, it was observed that by decreasing the effective fiber reinforcement ratio (percentage of fibers assessed in the loading direction), the tensile strength and modulus of elasticity are decreased.

Mastali, Mohammad, Valente, Isabel B., Barros, Joaquim A. O. (2017).

Flexural performance of innovative hybrid sandwich panels with special focus on the shear connection behaviour.

Paper submitted to Composite Structures, Elsevier, ISSN 0263-8223. 
Table 6. Mechanical properties obtained for GFRP skin and rib

\begin{tabular}{|c|c|c|c|c|c|c|}
\hline & $\begin{array}{l}\text { Coupon } \\
\text { specimens }\end{array}$ & Fiber distribution & $\begin{array}{l}\text { Extracted } \\
\text { GFRP } \\
\text { coupons } \\
\text { at }\end{array}$ & $\begin{array}{c}\text { Tensile } \\
\text { strength } \\
(\mathrm{MPa})\end{array}$ & $\begin{array}{c}\text { Modulus } \\
\text { of } \\
\text { elasticity } \\
\text { (GPa) }\end{array}$ & $\begin{array}{l}\text { Ultimate } \\
\text { strain } \\
(\%)\end{array}$ \\
\hline \multirow[t]{2}{*}{ Type 1} & 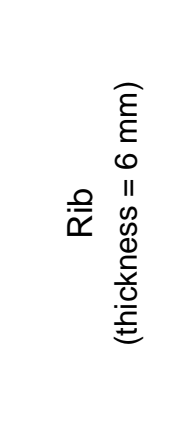 & $\begin{array}{c}1 \text { sheet of E-glass fibres } \\
\text { with } 600 \mathrm{~g} / \mathrm{m}^{2} \text { in } 0^{0^{*}} \\
\text { and } 40 \mathrm{~g} / \mathrm{m}^{2} \text { in } 90^{0^{*+}} \\
+ \\
15 \text { sheets of E-glass fibres: } \\
\text { each sheet has } 400 \mathrm{~g} / \mathrm{m}^{2} \text { in } \\
\pm 45^{0} \\
+ \\
1 \text { sheet of } \mathrm{E}-\text { glass fibres } \\
\text { with } 600 \mathrm{~g} / \mathrm{m}^{2} \text { in } 0^{0^{*}} \\
\text { and } 40 \mathrm{~g} / \mathrm{m}^{2} \text { in } 90^{0^{*+}}\end{array}$ & $\begin{array}{l}90^{\circ} \\
45^{\circ}\end{array}$ & $\begin{array}{r}98.35 \\
332.21\end{array}$ & $\begin{array}{l}13.01 \\
15.96\end{array}$ & $\begin{array}{l}11.70 \\
2.20\end{array}$ \\
\hline & 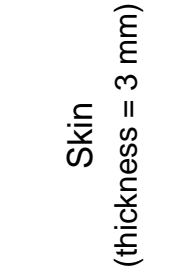 & $\begin{array}{c}6 \text { sheets of E-glass fibres: } \\
\text { each sheet has } \\
600 \mathrm{~g} / \mathrm{m}^{2} \text { in direction } 0^{0 *} \\
\text { and } 40 \mathrm{~g} / \mathrm{m}^{2} \text { in direction } 90^{0^{* *}}\end{array}$ & $90^{\circ}$ & 65.98 & 13.30 & 2.22 \\
\hline \multirow[t]{2}{*}{ Type 2} & 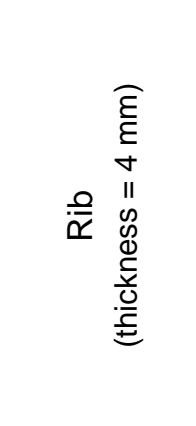 & 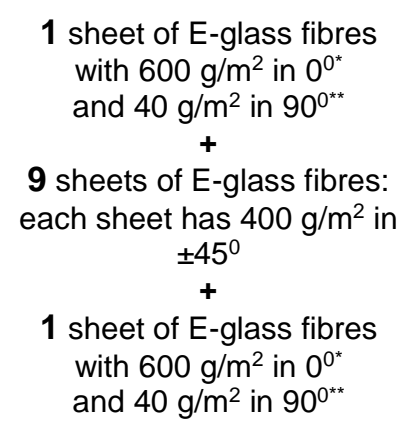 & $90^{\circ}$ & 174.00 & 13.03 & 2.40 \\
\hline & 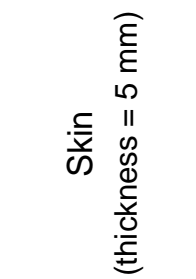 & $\begin{array}{c}10 \text { sheets of E-glass fibres: } \\
\text { each sheet has } \\
600 \mathrm{~g} / \mathrm{m}^{2} \text { in direction } 0^{0 *} \\
\text { and } 40 \mathrm{~g} / \mathrm{m}^{2} \text { in direction } 90^{* * *}\end{array}$ & $90^{\circ}$ & 63.03 & 36.06 & 1.66 \\
\hline
\end{tabular}

* 0 o corresponds to the skin/rib longitudinal direction

** $90^{\circ}$ corresponds to the skin/rib transversal direction

Mastali, Mohammad, Valente, Isabel B., Barros, Joaquim A. O. (2017).

Flexural performance of innovative hybrid sandwich panels with special focus on the shear connection behaviour.

Paper submitted to Composite Structures, Elsevier, ISSN 0263-8223. 


\subsubsection{Polyurethane foam core}

In the typical sandwich panels, premature failures dominate in the foam cores due to low shear and low tensile capacities to transfer shear stresses. To prevent the effect of premature failures, polyurethane foam core was not considered as a structural material in this study, and the shear stresses are transferred from top layer to bottom layer mainly through the GFRP ribs. Thus, polyurethane foam cores are only submitted to compressive loading. For this purpose, three polyurethane foam cores of $70 \times 70 \times 50 \mathrm{~mm}^{3}$ dimension and $42.5 \mathrm{~kg} / \mathrm{m}^{3}$ density were tested according to the ASTM C365-03 recommendations [9]. The compressive load was applied to the specimens at a displacement rate of $0.5 \mathrm{~mm} / \mathrm{min}$. The results showed a rigid-plastic response followed by a strain-hardening at large strain level, of about $0.3(\mathrm{~mm} / \mathrm{mm})$, with excessive compressive deformations. The measured plastic compressive strength and the compressive modulus of elasticity were $0.18 \mathrm{MPa}$ and $5.83 \mathrm{MPa}$, respectively.

\section{Geometry of the proposed shear connectors}

By executing pull-out tests, Lameiras et al. [10] have assessed the performance of some types of embedded GFRP connectors, including T shape profiled connectors and perforated connectors with holes of different arrangements. Connectors adhesively bonded to the concrete substrate (steel fiber reinforced self-compacting concrete) were also tested, but the observed failure was rather brittle. From these tests, it was concluded that embedded connectors provide high load carrying capacity, and significant deformation and post-peak load capacity [10]. Inspired in the research carried out by these authors, it was decided to use perforated shear connectors in hybrid slabs herein developed in order to ensure a proper shear connection between the GFRP rib and the DHCC layer [5].

A first group of two hybrid slabs, with the geometry proposed in Fig. 2 and detailed in Table 1, was built and tested. In these slabs, only perforated connectors with circular openings were considered. The corresponding results are reported in [5]. The nonlinearity observed in the response of the tested slabs was mainly caused by the damage occurred in the connection between GFRP ribs and DHCC layer due to high stress concentration around the perforated shear connectors $[5,11]$. Therefore, in the present paper, indented shear connectors are proposed with the objective of preventing or, at least delaying the occurrence of damage in GFRP ribs, and ensure a higher load carrying capacity. The indented openings in the GFRP ribs filled with DHCC material form larger dowels that increase the mechanical anchorage between the GFRP connectors and the DHCC layer (Fig. 7d).

Mastali, Mohammad, Valente, Isabel B., Barros, Joaquim A. O. (2017).

Flexural performance of innovative hybrid sandwich panels with special focus on the shear connection behaviour.

Paper submitted to Composite Structures, Elsevier, ISSN 0263-8223. 


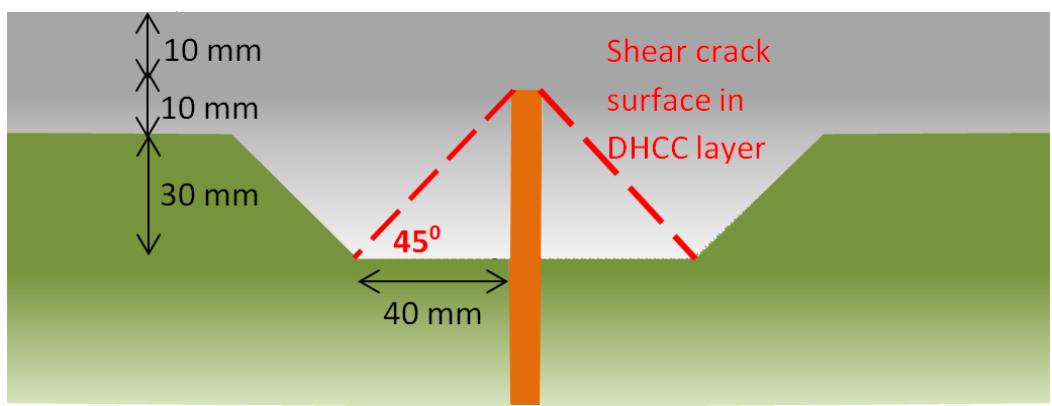

a)

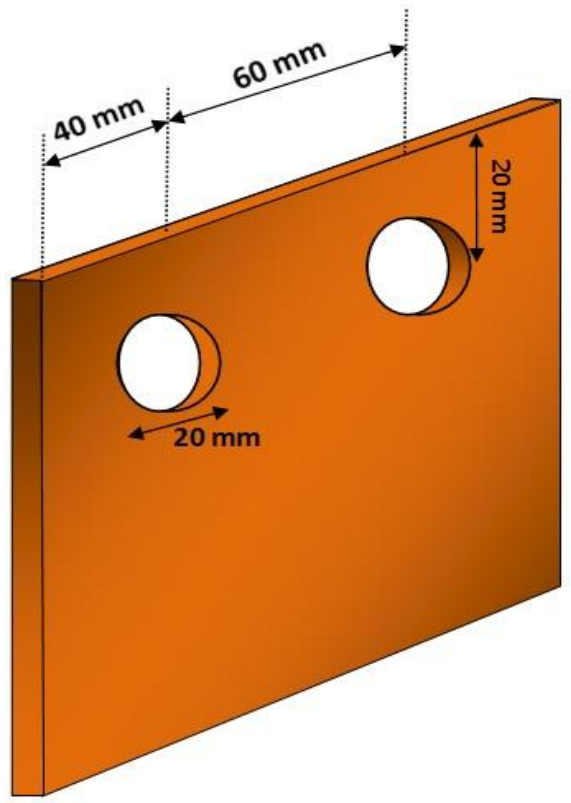

b)

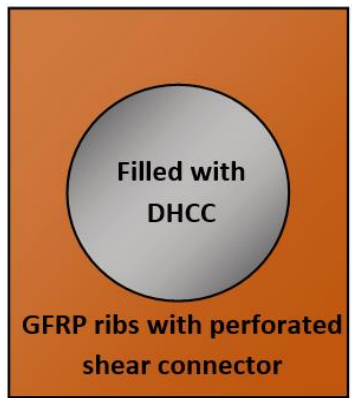

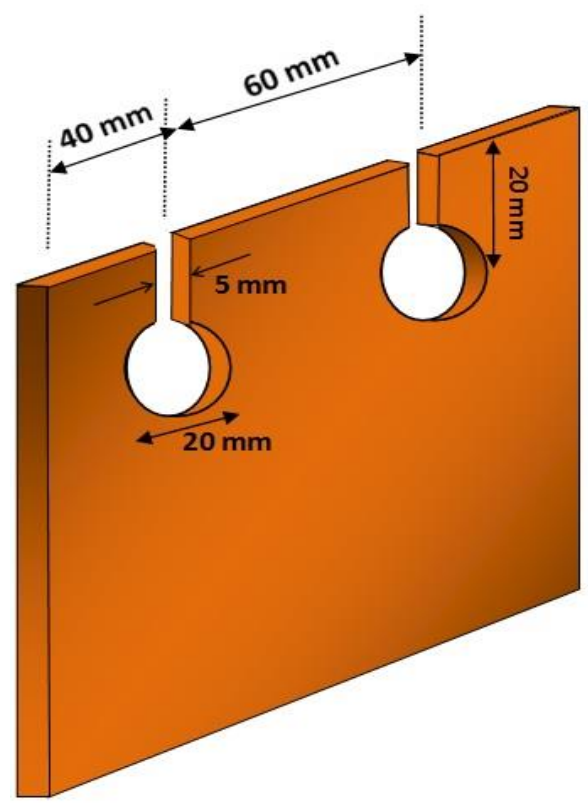

c)

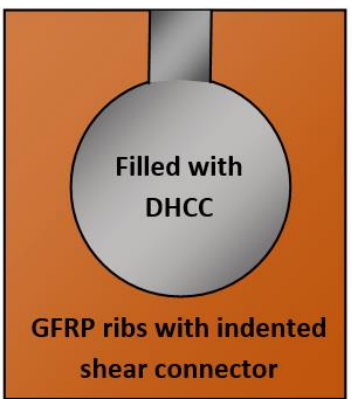

d)

Fig 7. Connection system between GFRP ribs and DHCC layer: a) Haunch area; b) Perforated shear connector; c) Indented shear connector; d) Larger dowels in indented shear connectors, in comparison to perforated shear connectors

Mastali, Mohammad, Valente, Isabel B., Barros, Joaquim A. O. (2017).

Flexural performance of innovative hybrid sandwich panels with special focus on the shear connection behaviour.

Paper submitted to Composite Structures, Elsevier, ISSN 0263-8223. 
To assess the flexural performance of hybrid sandwich panels with indented shear connectors, two slabs with $2000 \mathrm{~mm}$ length and $800 \mathrm{~mm}$ width were built and experimentally tested under FPB loading configuration. With the results obtained in these tests, the authors intend to execute a comparison between the results previously obtained with perforated shear connectors [5] and those determined in the proposed indented shear connectors.

The details of the perforated and indented shear connectors used in the built slabs are shown in Fig. 7b and Fig. 7c, respectively. To create shear connectors in GFRP ribs, circular holes with 20 $\mathrm{mm}$ diameter were executed on the top zone of the GFRP part that stays embedded in the DHCC layer after casting. To guarantee the embedment of the shear connectors in the DHCC layer, and also to decrease the susceptibility for the formation of cracks in the surface of the DHCC layer, a haunch area was designed in the DHCC layer. This trapezoidal shape is also an adequate solution to create a larger compression flange in the DHCC layer (see Fig. 7a).

Since flexible PAN fibers with maximum length of $12 \mathrm{~mm}$ are used in DHCC material, they can easily flow through the holes $(20 \mathrm{~mm})$ of the perforated and indented GFRP shear connectors.

The manufacture process of hybrid slabs is schematically shown in Fig. 8. The ribs and skins were produced through Vacuum Assisted Resin Transfer Molding (VARTM) process (details about VARTM process can be found in [5]). Afterwards, perforated and indented shear connectors were executed in the GFRP ribs with a simple drilling process. Finally, the DHCC was cast for forming the top layer.

Mastali, Mohammad, Valente, Isabel B., Barros, Joaquim A. O. (2017).

Flexural performance of innovative hybrid sandwich panels with special focus on the shear connection behaviour.

Paper submitted to Composite Structures, Elsevier, ISSN 0263-8223. 

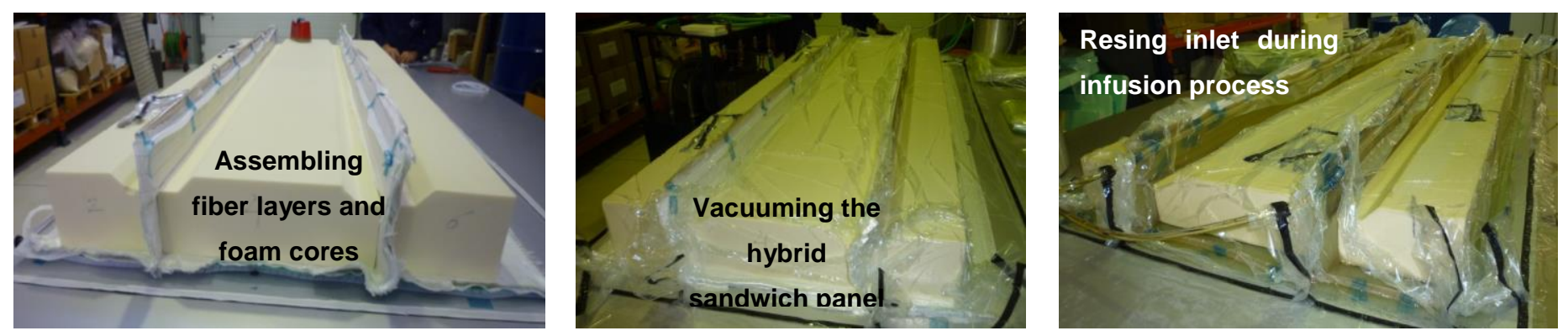

a)

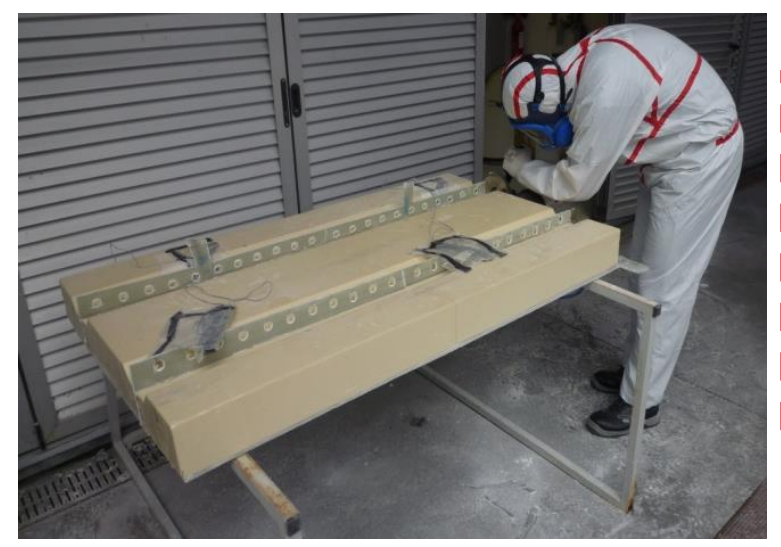

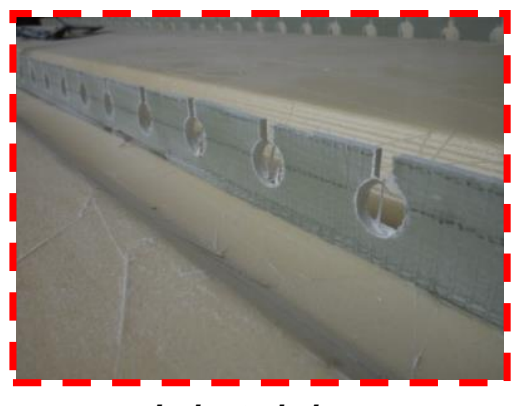

Indented shear

b)

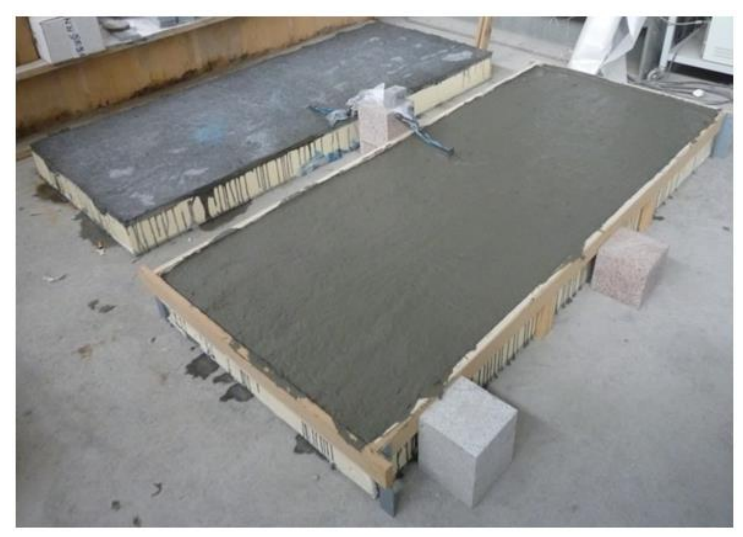

c)

Fig 8. Manufacturing process of the GFRP-DHCC sandwich panels: a) Producing GFRP skin and ribs through VARTM process; b) Executing perforated and indented connectors; c) Casting of DHCC layer

Mastali, Mohammad, Valente, Isabel B., Barros, Joaquim A. O. (2017).

Flexural performance of innovative hybrid sandwich panels with special focus on the shear connection behaviour.

Paper submitted to Composite Structures, Elsevier, ISSN 0263-8223. 


\section{Test setup and instrumentation}

Two slabs with indented shear connectors were tested under flexural FPB loading conditions to assess their flexural performance. Seven LVDTs were used to measure displacements in the different positions of slabs, as indicated in Fig. 9. Three LVDTs were mounted to record vertical deflections (LVDT 3, LVDT 4, and LVDT 5), two LVDTs measured vertical displacements at twoside supports (LVDT 2 and LVDT 6), and two LVDTs registered slip between GFRP rib and DHCC layer (LVDT 1 and LVDT 7) at both end sides, as indicated in Fig. 9a and Fig. 9b.

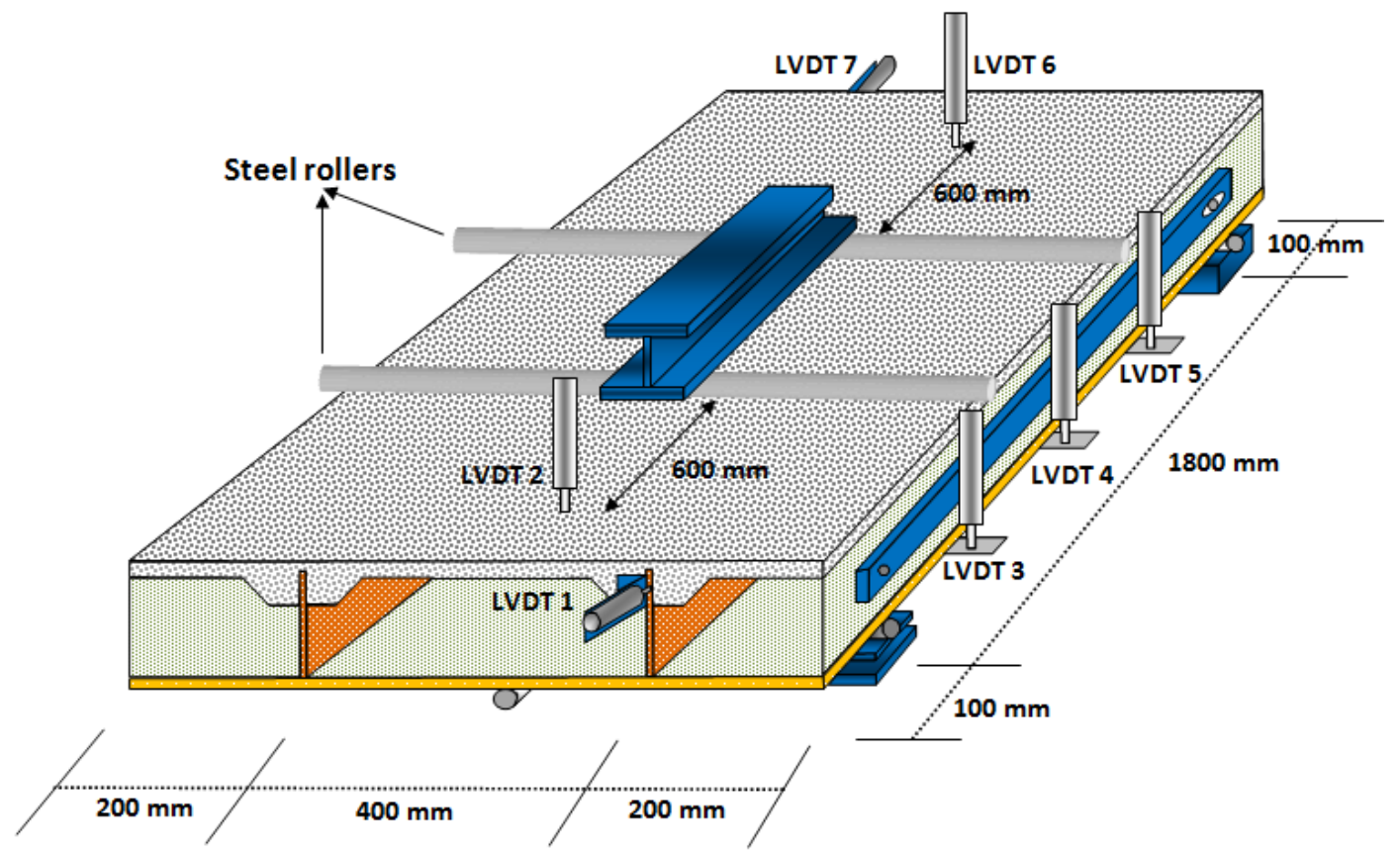

a)

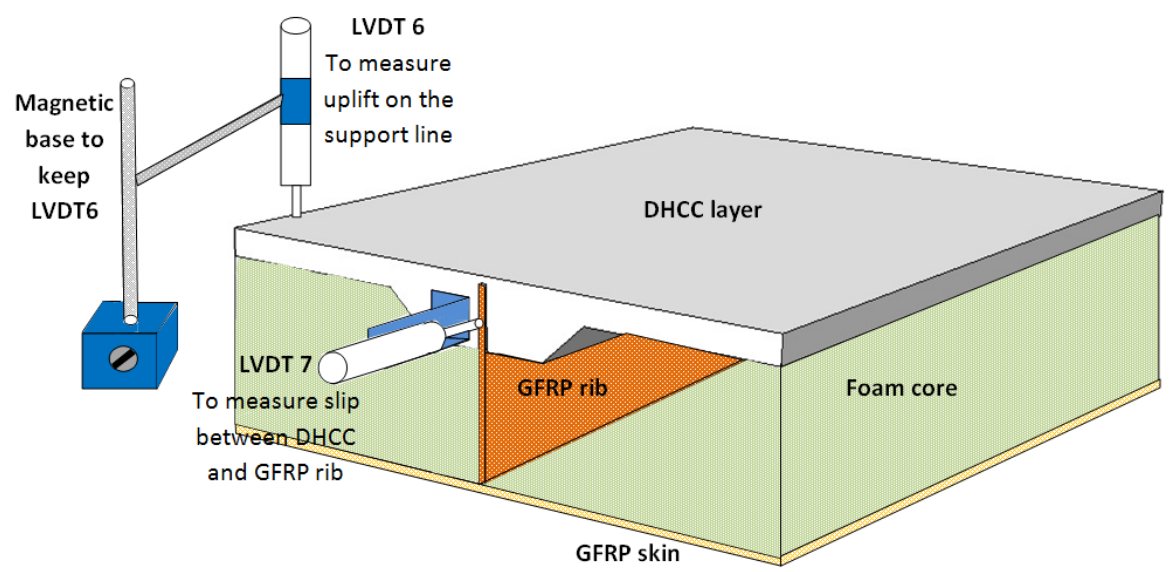

b)

Fig 9. a) Test setup and adopted instrumentation for measuring slab's deflection and GFRP-DHCC sliding; b) details of the instrumentation

Mastali, Mohammad, Valente, Isabel B., Barros, Joaquim A. O. (2017).

Flexural performance of innovative hybrid sandwich panels with special focus on the shear connection behaviour.

Paper submitted to Composite Structures, Elsevier, ISSN 0263-8223. 
The GFRP skin and ribs were instrumented with strain gauges of $5 \mathrm{~mm}$ measuring length. Two strain gauges were positioned in the GFRP rib, one strain gauge was installed at the bottom of GFRP skin, and one strain gauge was installed on top of DHCC layer, as shown in Fig. 10. The tests were carried out under monotonic FPB loading by applying a displacement rate of $30 \mu \mathrm{m} / \mathrm{sec}$ to the slab at mid-span.

\section{a) Strain gauge 1 positioned on the GFRP skin}

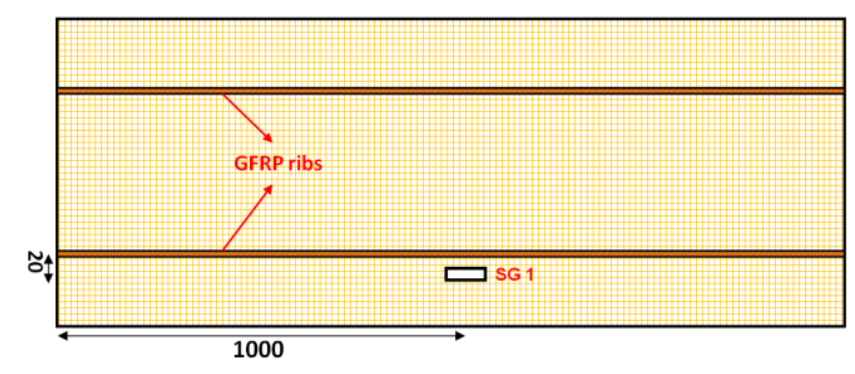

b) Strain gauges 2 and 3 positioned in the GFRP ribs

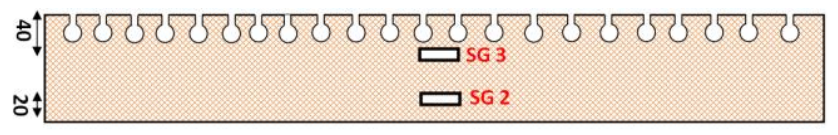

c) Strain gauge 4 positioned on
the DHCC layer

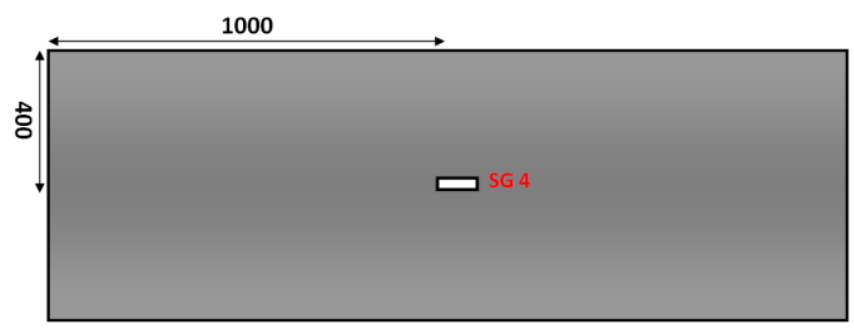

Fig 10. Positions of strain gauges in the hybrid sandwich panels tested

In order to compare the flexural performance of slabs with indented shear connectors and slabs with perforated connectors, it was important to adopt the same type of loading (FPB test), LVDT's locations, and imposed displacement rate that were previously taken into account in [5]. The behavior of the developed hybrid sandwich slabs with perforated shear connectors in [5] was assessed using two different flexural loading configurations: TPB, and FPB. Slab 1 was subjected to both TPB and FPB loading configurations, while Slab 2 was only submitted to FPB loading.

According to the load procedures defined in [5], two cycles were applied in each sequence of loading.

For Slab 1 with perforated shear connectors, the first step of loading was composed of the FPB test by applying two cycles with a maximum mid-span deflection of $14.4 \mathrm{~mm}(2 \delta$, where $\delta=\mathrm{L} / 250$

Mastali, Mohammad, Valente, Isabel B., Barros, Joaquim A. O. (2017).

Flexural performance of innovative hybrid sandwich panels with special focus on the shear connection behaviour.

Paper submitted to Composite Structures, Elsevier, ISSN 0263-8223. 
and $L=1800 \mathrm{~mm}$ ) [5]. After applying the first cyclic loading, Slab 1 was unloaded and subjected to a TPB cyclic loading with the same mid-span deflection. The third and the fourth loading steps were executed under FPB and TPB tests, respectively, by applying $21.6 \mathrm{~mm}(3 \delta)$ deflection at mid-span [5]. Then, in the last loading sequence, the mid-span deflection was increased up to $100 \mathrm{~mm}$ under FPB test, up to failure [5].

Slab 2, with perforated shear connectors, was submitted to a FPB cyclic loading. The first step of loading was performed by applying two cycles with a maximum mid-span deflection of $3.6 \mathrm{~mm}$

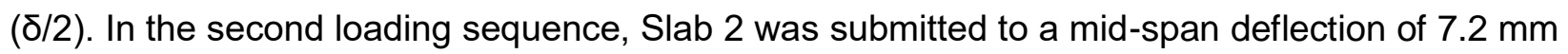
(ठ). The third and the fourth loading steps were carried out by imposing $10.8 \mathrm{~mm}(3 \delta / 2)$ and 14.4 $\mathrm{mm}(2 \delta)$ deflection at mid-span. Then, in the last loading sequence to Slab 2, the mid-span deflection was increased up to $80 \mathrm{~mm}$, up to failure [5].

The mid-span deflections applied to Slab 1 and Slab 2 were different. Based on the preliminary numerical simulations, severe damages were not expected up to a load level corresponding to the mid-span deflection of $14.4 \mathrm{~mm}(2 \delta)$, when a four point loading configuration is adopted. As the experimental response of Slab 1 during the first load sequence presented signs of damage, the increment of deflection adopted in the load sequences of Slab 2 was limited to $\delta / 2(\delta=L / 250$, with $L=1800 \mathrm{~mm}$ ) in order to have a first load sequence with a linear response [5].

\section{Experimental results}

In order to assess the flexural performance of the tested hybrid slabs, flexural loading was applied and the damage sequences were recorded. According to the observations made during the execution of experimental tests, five damage events occurred that were representative of all the tested specimens. The registered damage includes in a sequential manner:

1) Loss of connection between DHCC layer and foam core (Fig. 11a);

2) Damage in the GFRP ribs due to high compressive strains (Fig. 11b);

3) Slip between DHCC layer and GFRP ribs due to loss of bond (Fig. 11c);

4) Splitting cracks formed on the surface of DHCC layer in the alignment of the GFRP ribs (Fig. 11d);

5) Crushing of PU foam in the zones of the applied load lines (Fig. 11e).

Mastali, Mohammad, Valente, Isabel B., Barros, Joaquim A. O. (2017).

Flexural performance of innovative hybrid sandwich panels with special focus on the shear connection behaviour.

Paper submitted to Composite Structures, Elsevier, ISSN 0263-8223. 


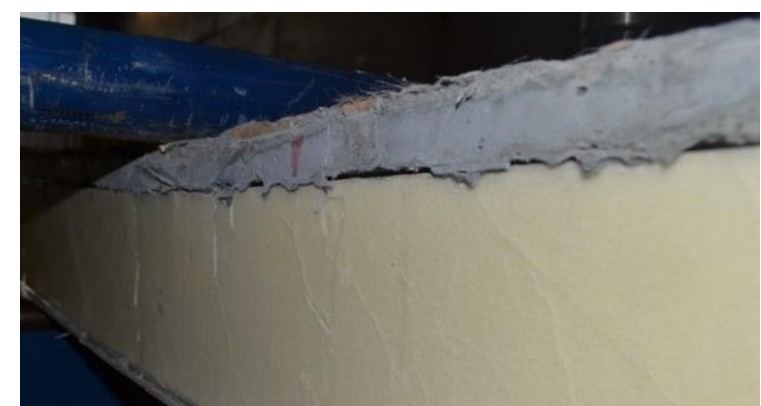

a) Loss of connection between DHCC layer and foam core

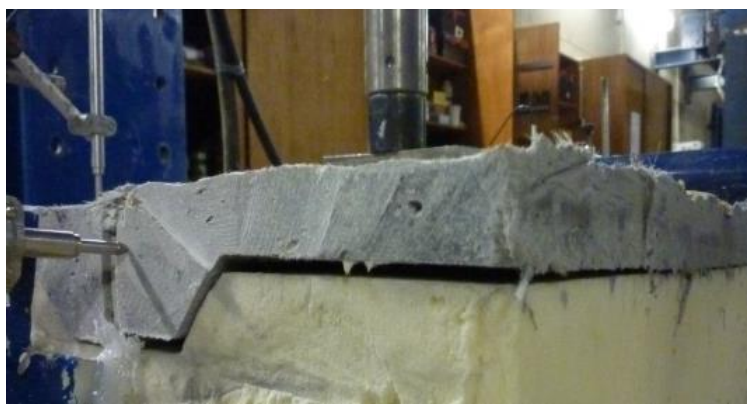

c) Slip between DHCC layer and GFRP ribs

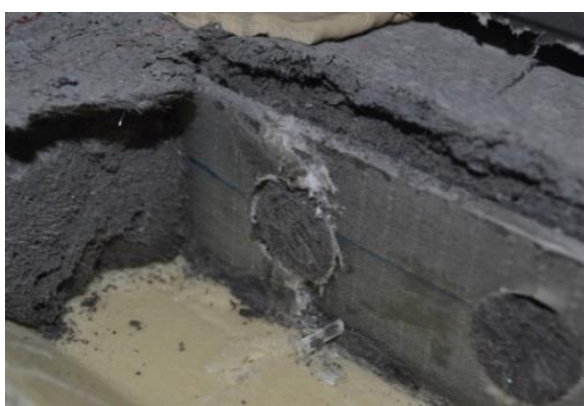

b) Compressive damage in the GFRP ribs

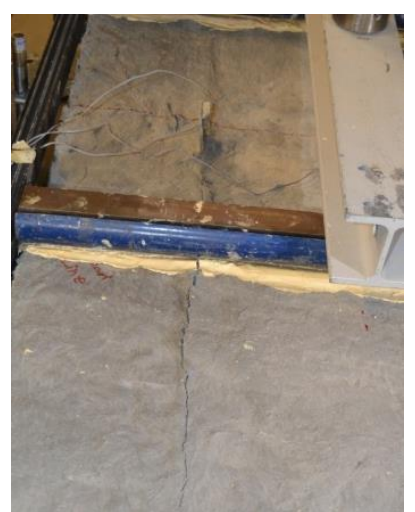

d) Splitting cracks in the DHCC layer in the alignment of the GFRP ribs

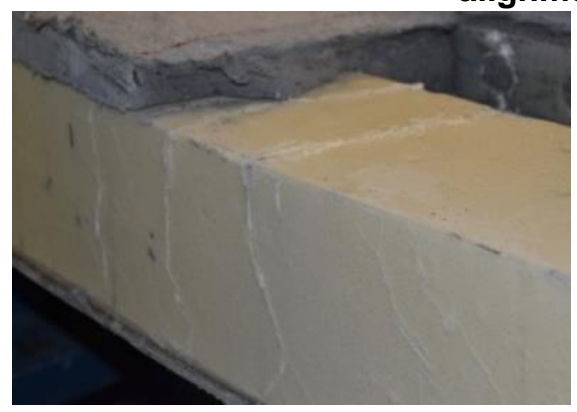

e) Crushing of PU foam

Fig 11. Damages observed during the execution of FPB slab tests

Comparing damage sequences reported in [5] and the damages observed in this study revealed that damage sequences were independent of the shear connector's type.

As shown in Fig. 12, using indented shear connectors instead of perforated shear connectors resulted in observing more compressive damages in the GFRP ribs. This may be a consequence of different stiffness amongst the DHCC dowels, and/or uniform distribution of compressive stresses within the GFRP ribs.

Mastali, Mohammad, Valente, Isabel B., Barros, Joaquim A. O. (2017).

Flexural performance of innovative hybrid sandwich panels with special focus on the shear connection behaviour.

Paper submitted to Composite Structures, Elsevier, ISSN 0263-8223. 


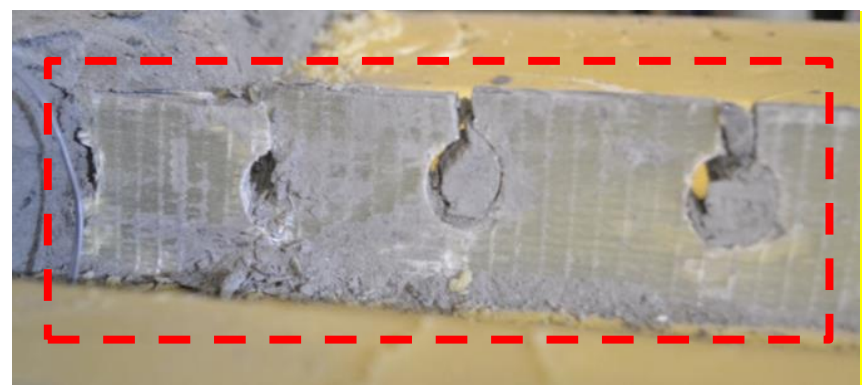

a)

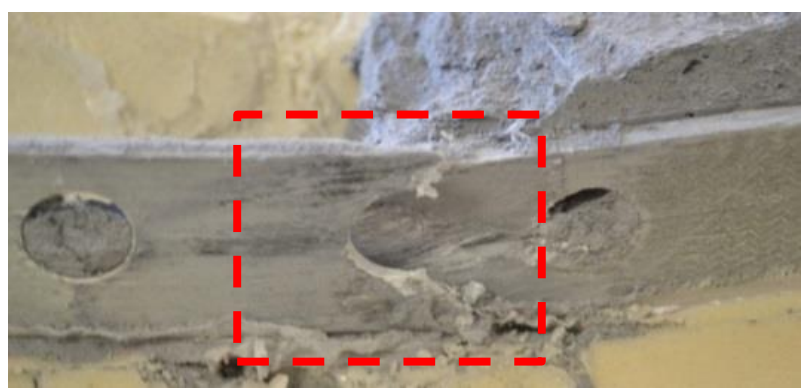

b)

Fig 12. Compressive damage in Slab 1 with: a) Indented shear connectors; b) Perforated shear connectors [5]

\subsection{Interpretation of experimental results}

The force-mid span deflection response obtained in the FRP tests carried out with the developed hybrid sandwich slabs is presented in Fig. 13. 


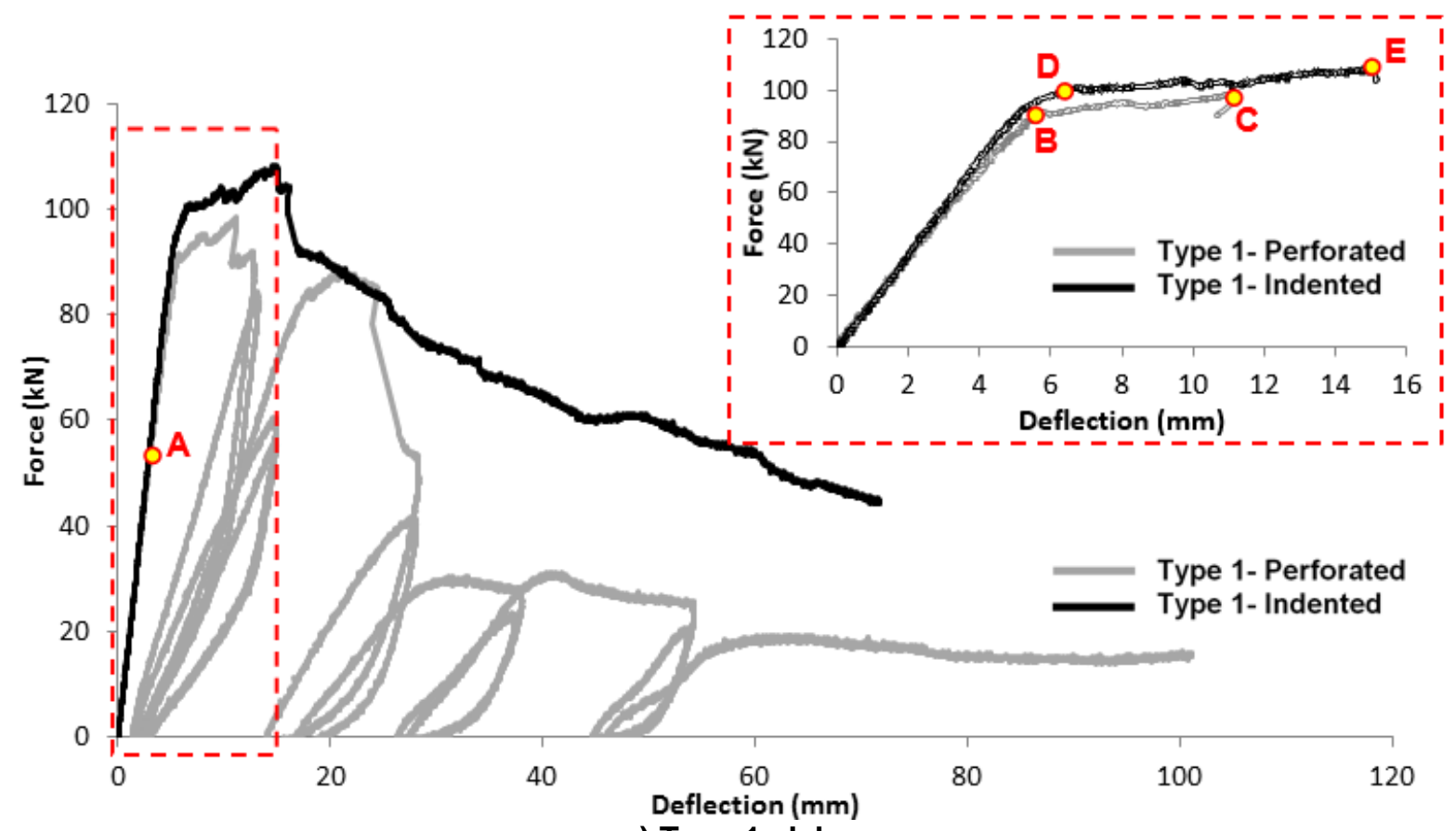

a) Type 1 slabs

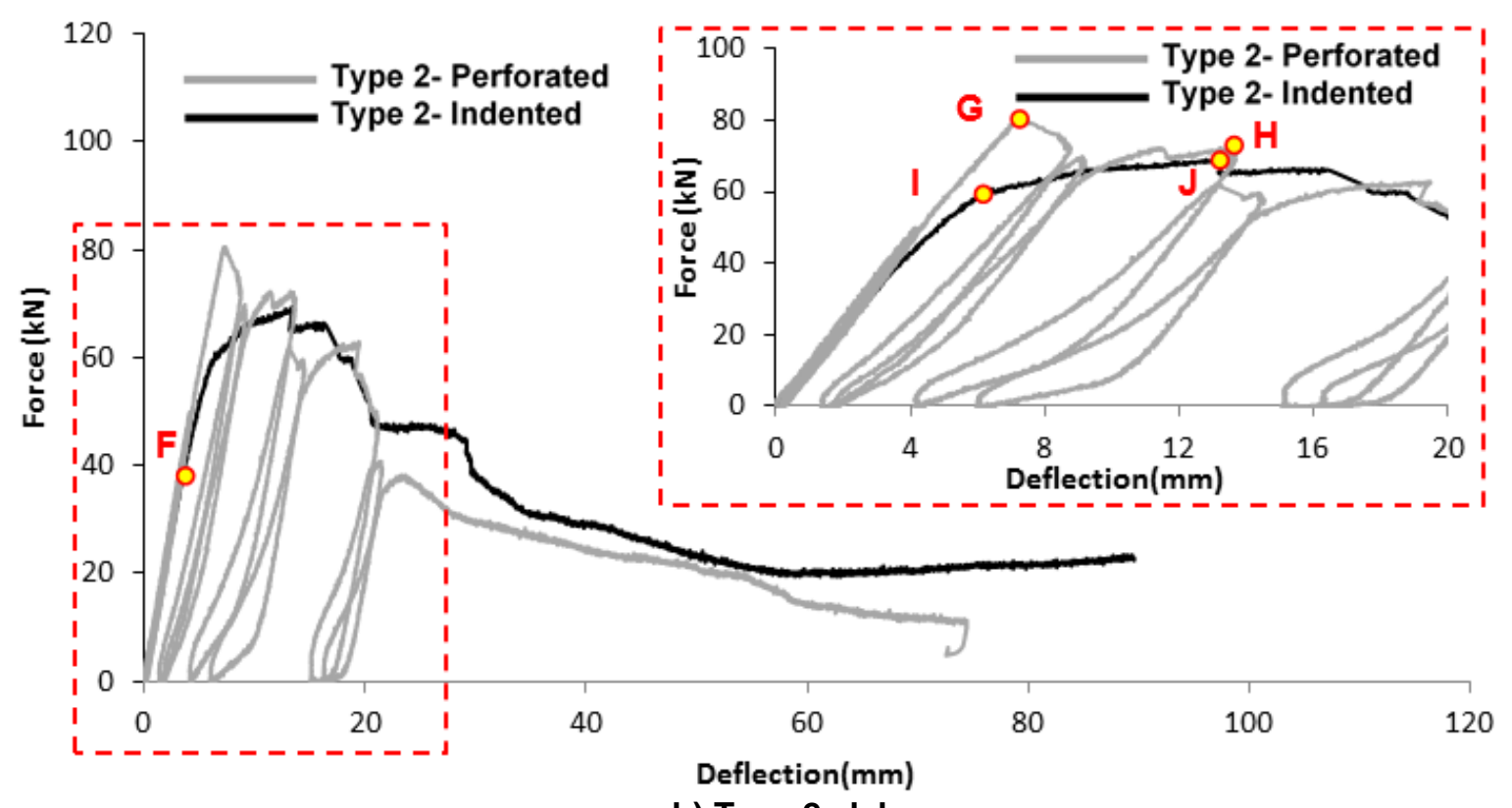

b) Type 2 slabs

Fig 13. Force-deflection responses of the developed hybrid sandwich panels: a) Type 1; b) Type 2 (see also Table 6 and Fig 2)

Mastali, Mohammad, Valente, Isabel B., Barros, Joaquim A. O. (2017).

Flexural performance of innovative hybrid sandwich panels with special focus on the shear connection behaviour.

Paper submitted to Composite Structures, Elsevier, ISSN 0263-8223. 
Concerning the results indicated in Fig. 13a, the load carrying capacity and the residual strength are higher in Type 1 slab with indented shear connectors than in Type 1 slab with perforated shear connectors. This increase in the slabs with indented shear connectors could be justified by increasing the mechanical anchorage between the GFRP connectors and the DHCC layer.

Regardless the type of shear connector used, Type 1 slabs lost connection between DHCC layer and foam core at a load of $53.00 \mathrm{kN}$ (represented by point A in Fig. 13a and corresponding to the damage identified in Fig. 11a). This detachment did not have any impact in terms of changing the stiffness and the load carrying capacity of the tested slabs, which means that the shear forces are mainly transferred through the shear connectors.

In Type 1 slab with perforated shear connectors, compressive damage in the GFRP ribs occurred at the load of $91.53 \mathrm{kN}$ and a corresponding deflection of $5.63 \mathrm{~mm}$ (Point B in Fig. 13a and compressive damage in GFRP ribs, see Fig. 11b). In Type 1 slab with indented shear connectors, compressive damage in the GFRP ribs was registered at a load $99.97 \mathrm{kN}$ and a corresponding deflection of $6.37 \mathrm{~mm}$ (Point D in Fig. 13a). Afterwards, a pronounced nonlinear behavior occurred due to the propagation of damage in both Type 1 slabs. Type 1 slab with perforated shear connectors presented a hardening response in the deflection interval of $5.63 \mathrm{~mm}$ to $10.61 \mathrm{~mm}$, while a hardening stage of larger deflection amplitude (from $6.37 \mathrm{~mm}$ to $14.80 \mathrm{~mm}$ ) has developed when using indented shear connectors (point $E$ in Fig. 13a). At the maximum deflection of these hardening stage intervals, the Slab 1 with perforated and indented shear connectors presented a load capacity (maximum value) of $97.48 \mathrm{kN}$ and $108.53 \mathrm{kN}$, respectively, corresponding to Point $\mathrm{C}$ and Point E in Fig 13a.

For a deflection of $71 \mathrm{~mm}(\approx \mathrm{L} / 25)$, the Type 1 slab with indented and perforated shear connectors presented a residual load carrying capacity of $45.00 \mathrm{kN}$ and $14.5 \mathrm{kN}$, respectively, that correspond to $44 \%$ and $15 \%$ of their corresponding peak load. This shows the higher effectiveness of the indented shear connectors in the post-peak load carrying capacity of this type of slabs.

A similar approach was followed to assess Type 2 slabs under flexural loading. The registered results are presented in Fig. 13b. Regardless of the shear connector used, the connection between DHCC layer and foam core was lost at a load of $40.00 \mathrm{kN}$ without visible damage or significant impact in terms of loss of stiffness (Points F in Fig. 13b). This behavior was similar to the one previously observed in Type 1 slabs.

Mastali, Mohammad, Valente, Isabel B., Barros, Joaquim A. O. (2017).

Flexural performance of innovative hybrid sandwich panels with special focus on the shear connection behaviour.

Paper submitted to Composite Structures, Elsevier, ISSN 0263-8223. 
The compressive damage in the GFRP ribs of Type 2 slab with perforated shear connectors occurred at a load of $80.58 \mathrm{kN}$ and deflection of $7.02 \mathrm{~mm}$ (Point G in Fig. 13b), while Type $2 \mathrm{slab}$ with indented connectors suffered compressive damage, at a load of $58.96 \mathrm{kN}$ and $6.07 \mathrm{~mm}$ of mid-span deflection (Point I in Fig. 13b). Despite the compressive damage verified in GFRP ribs of Type 2 slab with indented shear connectors, a pseudo-hardening stage was observed in the deflection interval of $6.07 \mathrm{~mm}$ to $13.36 \mathrm{~mm}$ (Point I to Point $\mathrm{J}$ in Fig. 13b), and a peak load of $69.37 \mathrm{kN}$ was attained at the end of this hardening stage. Above this deflection, this slab entered in a softening phase. For a deflection of $75 \mathrm{~mm}(\approx \mathrm{L} / 24)$, the Type 2 slab with indented and perforated shear connectors presented a residual load carrying capacity of $21.10 \mathrm{kN}$ and 10.77 $\mathrm{kN}$, respectively, that correspond to $30 \%$ and $14 \%$ of their corresponding peak load.

Together with the results already presented, for Type 1 slabs Type 2 slabs, it can be concluded that indented shear connectors can be more effective on providing a higher residual strength than perforated ones, which means a higher reserve of load carrying capacity in extreme loading conditions. Using indented shear connectors resulted in increasing the contact area of the GFRP rib that are transferring shear force to the surrounding DHCC material in comparison to perforated shear connectors. This increase may have led to a more effective contribution of fiber reinforcement mechanisms in bridging the formed cracks in the DHCC. In addition, the indented configuration of the shear connector diminishes the stiffness of the part of the GFRP rib that is embedded in the DHCC layer, which has a favorable impact in terms of damage level in both the GFRP rib and DHCC layer.

The type of shear connector has marginal effect in terms of maximum load capacity in both types of slabs. Table 7 summarizes the results obtained in the tested slabs, where $P_{\max }$ is the maximum load, while $\delta_{P_{\max }}$ and $S_{P_{\max }}$ are the corresponding mid span deflection and slip measured at the slabs' supports, respectively. Table 7 also indicates the maximum load and its corresponding mid span deflection when the elastic response of the slabs ends, $P_{\max , l i n}$ and $\delta_{P_{\max , l i n}}$ respectively, as well as the slab's flexural stiffness at this loading stage, obtained from equation (3):

$$
(E I)_{\text {Slab }}^{\exp }=\frac{23 P_{\text {max }, \text { lin }} L^{3}}{648 \delta_{P_{\text {max }, \text { lin }}}}
$$

where $L$ is the span length (1800 mm, Fig. 9a).

Mastali, Mohammad, Valente, Isabel B., Barros, Joaquim A. O. (2017).

Flexural performance of innovative hybrid sandwich panels with special focus on the shear connection behaviour.

Paper submitted to Composite Structures, Elsevier, ISSN 0263-8223. 
The values of flexural stiffness presented in Table 7 indicate that using indented shear connectors instead of perforated shear connectors in Slab 1 increased about 7\% the elastic flexural stiffness, while using indented shear connectors instead of perforated shear connectors in Slab 2 reduced about $16 \%$ the elastic flexural stiffness.

Table 7. Relevant results obtained in hybrid GFRP-DHCC slabs

\begin{tabular}{cccccccc}
\hline $\begin{array}{c}\text { Slab } \\
\text { type }\end{array}$ & $\begin{array}{c}\text { Shear } \\
\text { connectors }\end{array}$ & $\begin{array}{c}P_{\max } \\
(\mathrm{kN})\end{array}$ & $\begin{array}{c}\delta_{P_{\max }} \\
(\mathrm{mm})\end{array}$ & $\begin{array}{c}S_{P_{\max }} \\
(\mathrm{mm})\end{array}$ & $\begin{array}{c}P_{\max , \text { lin }} \\
(\mathrm{kN})\end{array}$ & $\begin{array}{c}\delta_{P_{\max , \text { in }}} \\
(\mathrm{mm})\end{array}$ & $\begin{array}{c}(E I)_{\text {Slab }}^{\text {exp }} \\
\left(\mathrm{kN} . \mathrm{m}^{2}\right)\end{array}$ \\
\hline \multirow{2}{*}{ Type 1 } & Perforated & 97.48 & 10.61 & 0.014 & 91.53 & 5.63 & 3365 \\
& Indented & 108.53 & 14.80 & 3.83 & 94.97 & 5.46 & 3600 \\
\hline \multirow{2}{*}{ Type 2 } & Perforated & 71.51 & 13.55 & 1.98 & 80.58 & 7.02 & 2376 \\
& Indented & 69.37 & 13.36 & 0.29 & 59.94 & 6.07 & 2044 \\
\hline
\end{tabular}

Figs $14 \mathrm{a}$ and $14 \mathrm{~b}$ present the force and corresponding slip measured between the DHCC layer and the GFRP ribs (from LVDT1 and LVDT7, Fig. 9). In both types of slabs, regardless the type of connector, the slip is less than $0.015 \mathrm{~mm}$ in the phase corresponding to the linear behavior, and an abrupt increase of slip almost coincided with the initiation of the nonlinear response of the slabs. In Type 1 slab with perforated shear connectors, this slip increased occurred when the slab entered in its post-peak softening stage, while in the Type 1 slab with indented connectors a gradual increase of slip jump up to $3.76 \mathrm{~mm}$ has occurred during the hardening stage of this slab, which indicates the capacity of these connectors distribute the damage more uniformly during this critical loading stage of the slab. Up to peak load of the Type 2 slabs, the slip was larger in the slab with indented connectors, by the reasons previously exposed, but in their post-peak softening stage a larger slip was measured when using perforated connectors. This may be justified by the smaller stiffness (smaller thickness) of this connector $(4 \mathrm{~mm})$ when compared to the stiffness of the connector adopted in Type $1 \mathrm{slab}(6 \mathrm{~mm})$.

Mastali, Mohammad, Valente, Isabel B., Barros, Joaquim A. O. (2017).

Flexural performance of innovative hybrid sandwich panels with special focus on the shear connection behaviour.

Paper submitted to Composite Structures, Elsevier, ISSN 0263-8223. 


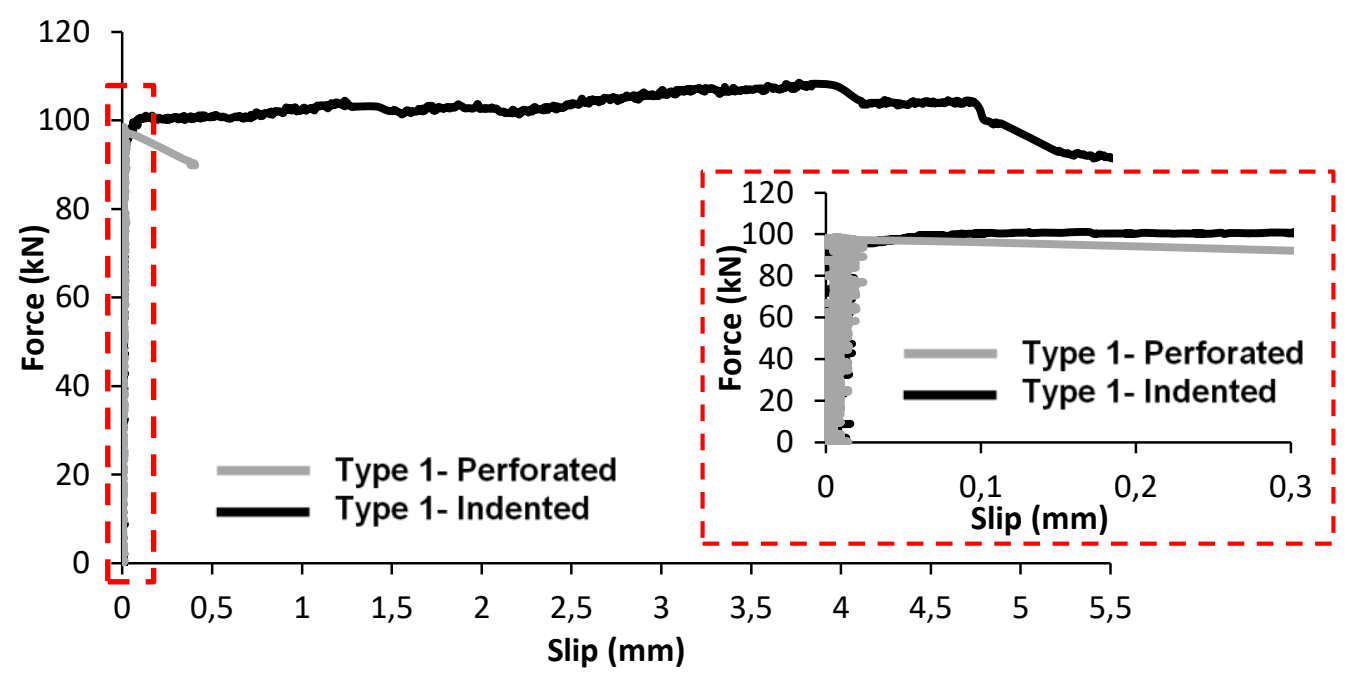

a) Type 1 slabs
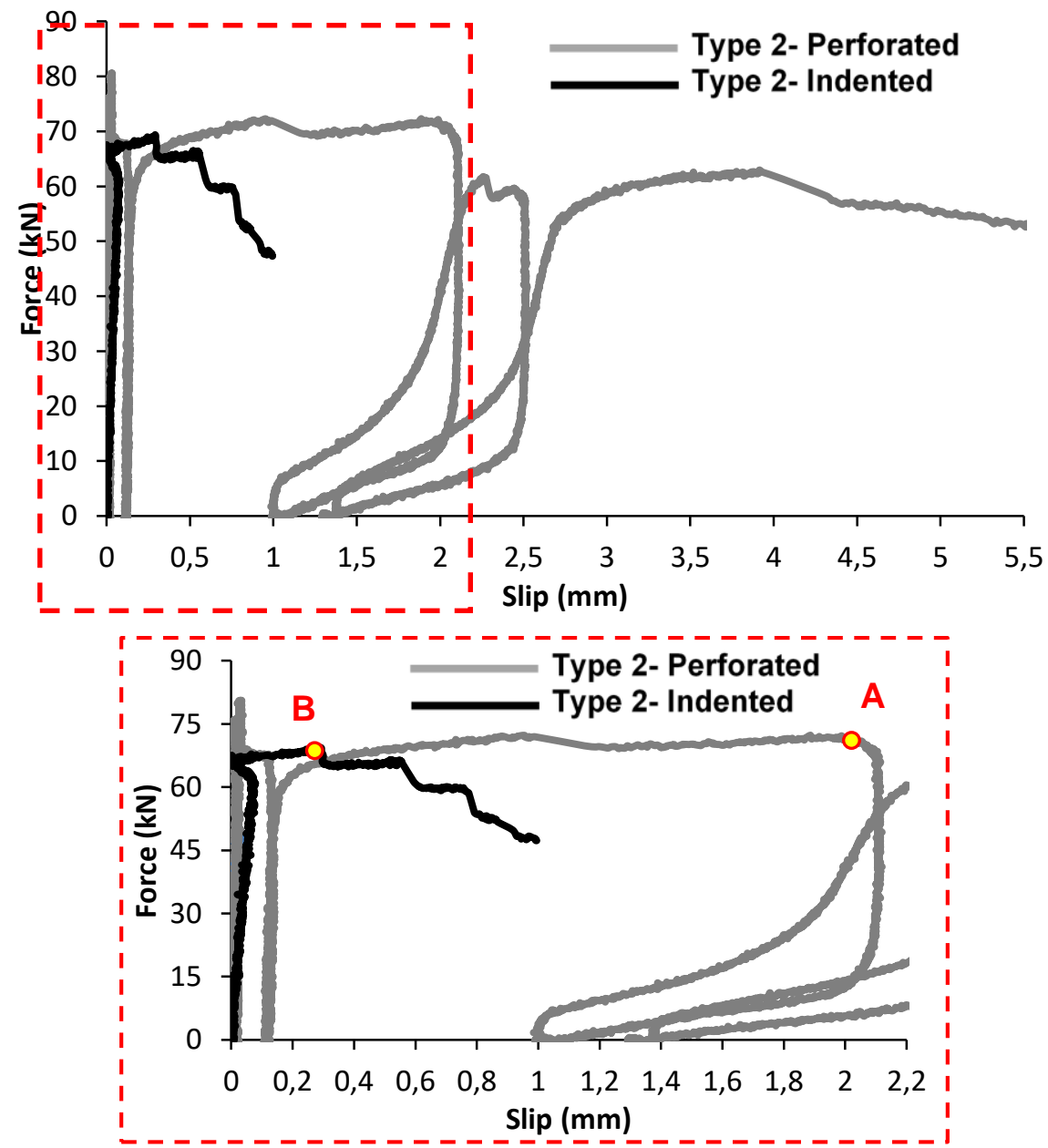

b) Type 2 slabs

Fig 14. a) Diagrams of force versus slip between GFRP rib and DHCC layer for: Type 1 slabs; b) Type 2 slabs

Mastali, Mohammad, Valente, Isabel B., Barros, Joaquim A. O. (2017).

Flexural performance of innovative hybrid sandwich panels with special focus on the shear connection behaviour.

Paper submitted to Composite Structures, Elsevier, ISSN 0263-8223. 
As previously mentioned in Section 4 and represented in Fig. 10, hybrid slabs with indented shear connectors were monitored with one strain gauge at the bottom of the GFRP skin (SG 1), two strain gauges in the GFRP rib, and one strain gauge on the upper face of the DHCC layer. Fig. 15 illustrates the variation of strain during the loading process. Maximum tensile and compressive strains of $0.0013(\mathrm{~mm} / \mathrm{mm})$ and $-0.00033(\mathrm{~mm} / \mathrm{mm})$ were registered in the GFRP skin (SG 1) and in the DHCC layer (SG 4), respectively, of Type 1 slab with indented connectors, as shown in Fig. 15a. The tensile strains measured in the GFRP skin were much lower than the ultimate strains recorded in the direct tensile tests carried out with specimens extracted from these components of the slab (see Table 6). Using indented shear connectors results in almost linear tensile strains in the GFRP skins, even during the deflection hardening stage identified for Type 1 slab. This indicates that the damage is mostly concentrated in the connection between GFRP ribs and DHCC layer, and the hardening behavior corresponds to the stage of slipping occurred in the interface of the two materials.

The strains recorded in the different positions of Type 2 slab with indented connectors are shown in Fig. 15b. A maximum tensile strain of $0.00086(\mathrm{~mm} / \mathrm{mm})$ was recorded in the GFRP skin and a maximum compressive strain of $-0.00058(\mathrm{~mm} / \mathrm{mm})$ was measured in the GFRP rib, while a compressive strain of $-0.00023(\mathrm{~mm} / \mathrm{mm})$ was recorded in the DHCC layer (SG 4). The maximum tensile strains also measured in the GFRP skin of Type 2 slab were much lower than the ultimate strains recorded in the direct tensile tests executed in the specimens extracted from these GFRP elements (see Table 6), therefore the conclusions already pointed out for Type 1 slab are also applied to Type 2 slab.

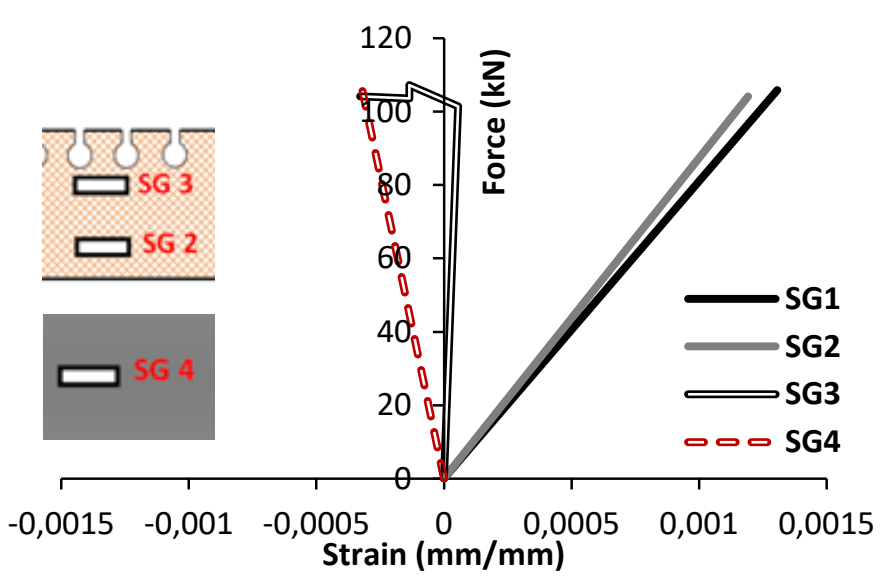

a)

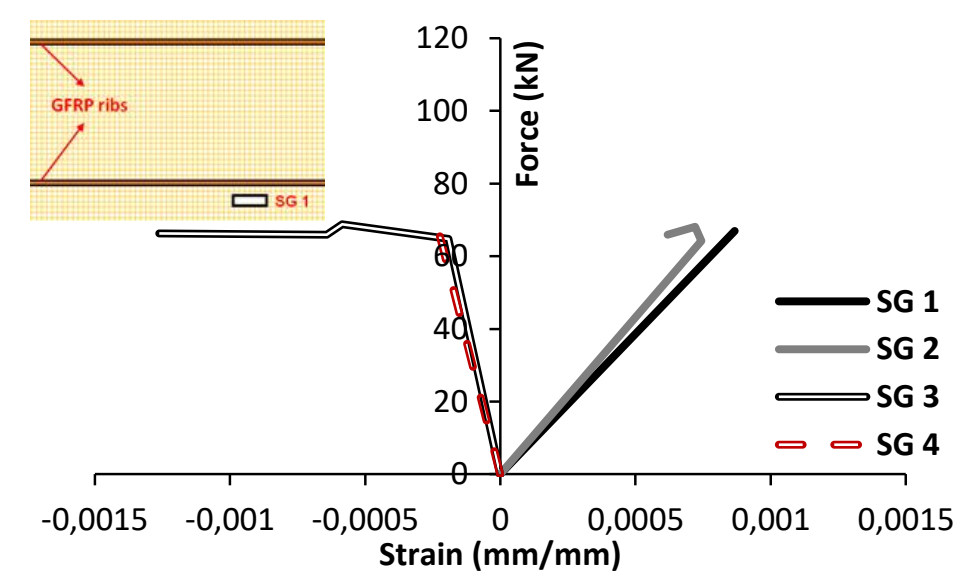

b)

Fig 15. Recorded strains in hybrid slabs with indented connectors: a) Type 1; b) Type 2

Mastali, Mohammad, Valente, Isabel B., Barros, Joaquim A. O. (2017).

Flexural performance of innovative hybrid sandwich panels with special focus on the shear connection behaviour.

Paper submitted to Composite Structures, Elsevier, ISSN 0263-8223. 


\subsection{Analysis and discussion}

The efficiency of the shear connectors used in this study was also evaluated by considering the strain distribution across the panel's thickness, at mid span. The curves represented in Fig. 16 correspond to different load levels that were established considering ratios between applied load and maximum load, resulting in the following: $20 \%, 40 \%, 60 \%, 80 \%$ and $100 \%$ of $P_{\max }$.

It is worth mentioning that no strain gauge was installed on the top layer of DHCC material of the slabs with perforated shear connectors.

As mentioned before, one strain gauge was installed on the top layer of DHCC material to measure compressive strains in the slabs with indented shear connectors. These strains were used to evaluate the efficiency of the indented shear connector, by analyzing the distribution of strains across the panels' thickness.

The authors are aware that the distribution of strains obtained for maximum load, across the panels' thickness are influenced by the significant slip values measured between the DHCC layer and the GFRP ribs at this load level. Additionally, when crushing started occurring in DHCC, as well as splitting cracks, the accuracy of the strains measured in the strain gauge installed on the top of the DHCC layer is questionable. The curves in Fig. 16 demonstrate that above a load level of $80 \%$ in Type 1 slab, and above $60 \%$ in Type 2 slab, sliding between DHCC layer and GFRP ribs has occurred, since the gradient of strains in the DHCC become smaller than in the top part of the GFRP rib. The anticipation of sliding in the type 2 slab can be justified by the smallest thickness/stiffness of its GFRP rib. The largest gradient of strains recorded in the strain gauge applied in the bottom part of the GFRP rib when compared to the gradient of strains in the GFRP skin, which was accentuated during the loading process, demonstrates a certain nonhomogeneity on the connection between these two GFRP components. The different strain gradients above reported are relatively small up to the indicated load levels, therefore a quasimonolithic condition can be assumed for these loading conditions.

Mastali, Mohammad, Valente, Isabel B., Barros, Joaquim A. O. (2017).

Flexural performance of innovative hybrid sandwich panels with special focus on the shear connection behaviour.

Paper submitted to Composite Structures, Elsevier, ISSN 0263-8223. 

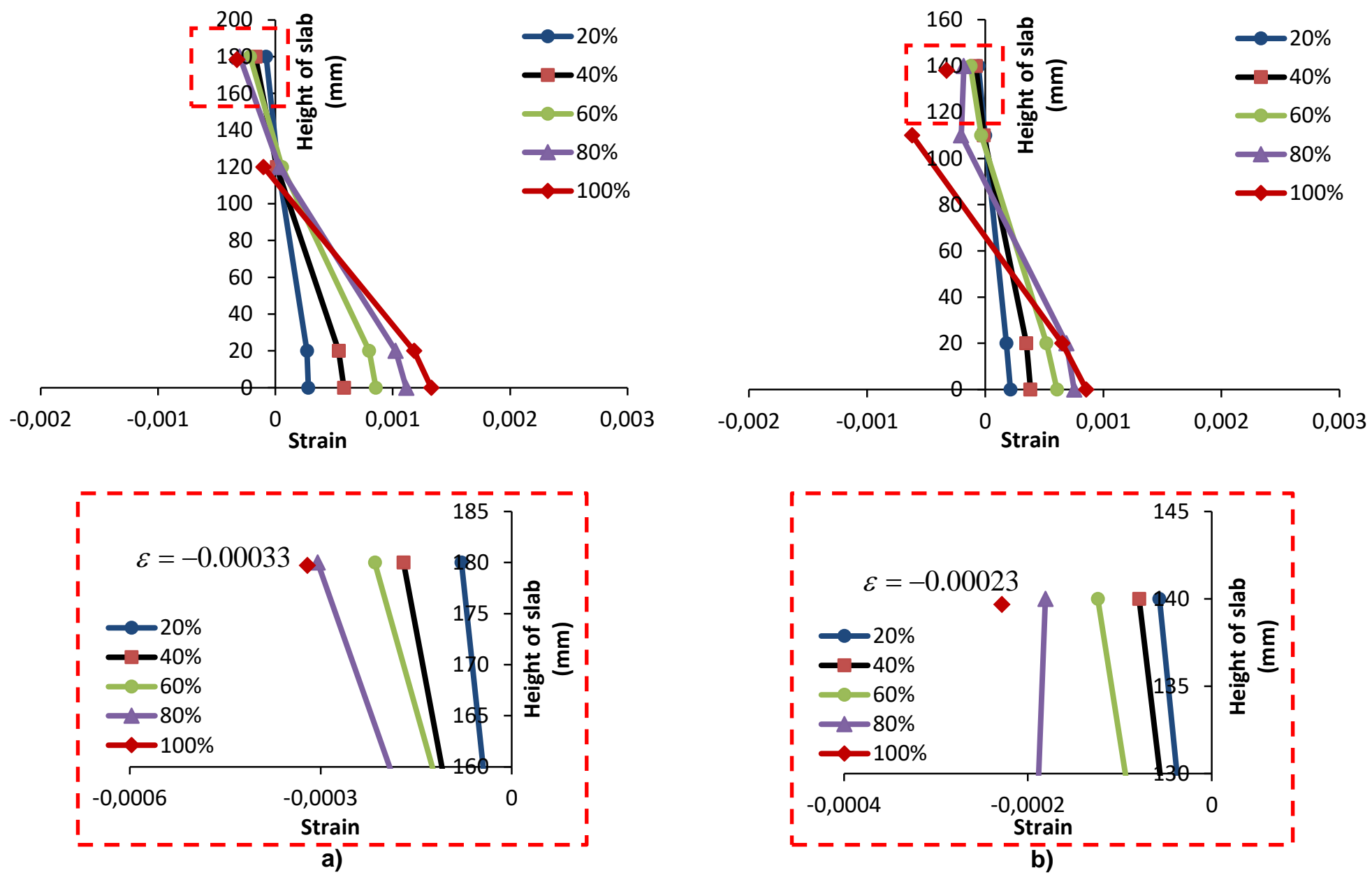

Fig 16. Strains in cross section of: a) Type 1 slab with indented shear connectors; b) Type 2 slab with indented shear connectors

In a composite element, full-composite action is attained when there is no slip between two or more elements connected. In this case, shear stresses are fully transmitted between layers and the strain diagram remain linear across the slab thickness. If the connection is not rigid, there is some slip between layers and the strain diagram is not continuous.

The distribution of strain across the panels' thickness in Type 1 and Type 2 slabs with indented shear connectors was analyzed to estimate the level of composite action.

Fig. 16a shows the distribution of strains across the panels' thickness in the different phases of loading for Type 1 slab with indented shear connectors. For $P_{\max }$, the strain diagram is not linear anymore, indicating a partial composite behavior at this loading stage. This means that between $0.8 P_{\max }$ and $P_{\max }$, some damage occurred in the connection that altered the transmission of shear stresses. This effect was previously identified in Fig. 11 and Fig. 13, where non-linear behavior

Mastali, Mohammad, Valente, Isabel B., Barros, Joaquim A. O. (2017).

Flexural performance of innovative hybrid sandwich panels with special focus on the shear connection behaviour.

Paper submitted to Composite Structures, Elsevier, ISSN 0263-8223. 
was observed for loads higher than $99.97 \mathrm{kN}$ (this value corresponds to $0.92 P_{\max }$ ) due to compressive damage in the GFRP ribs.

Type 2 slab with indented shear connectors shows an almost fully composite behavior up to $0.6 P_{\max }$, as shown in Fig $16 \mathrm{~b}$. Due to propagation of damage, by applying loads that are higher than $0.6 P_{\max }$ a partial composite action is obtained.

The degree of composite action during the initial phase of loading was evaluated for each specimen. The method defined by Pessiki and Mlynarczyk [12] was used together with the values of initial stiffness obtained in the experimental tests performed, and also considering the results from the numerical models developed. The experimental moment of inertia was calculated for each specimen using equation (2). The degree of composite action was calculated by comparing the experimental moment of the inertia of specimens $\left(I_{\exp }\right)$ and the corresponding numerical values for full-composite action $\left(I_{\mathrm{fc}}\right)$ and non-composite action $\left(I_{\mathrm{nc}}\right)$. Equation (4) is used to calculate the degree of composite action associated to the initial phase of loading.

$$
\kappa=\frac{\left(I_{\exp }-I_{n c}\right)}{\left(I_{f c}-I_{n c}\right)} \times 100(\%)
$$

It is worth mentioning that the moment of inertia of full-composite action $\left(I_{f c}\right)$ and non-composite action $\left(I_{n c}\right)$ are calculated in slabs without damage. To determine the numerical moment of inertia of full-composite action and non-composite action of hybrid slabs, a three dimensional nonlinear finite element model that can capture the force/deflection response of the hybrid sandwich panels was used. The three-dimensional FEM models developed within this study were calibrated with the experimental results previously presented in this paper and in [5]. The numerical models were simulated in ABAQUS software, which is a commercial software with several FEM-based potentialities for a multi-physics modeling in structural analysis [11, 13].

The numerical models in [5] developed with smaller errors than $8 \%$ for force, $7 \%$ for deflection, and $5 \%$ for stiffness, when compared to experimental results. Moreover, the experimental and numerical results indicated good agreement in terms of force versus strain response. In addition, the damages observed in the numerical models were consistent with the experimental results.

The main objective of modeling the hybrid slabs with full-composite action and non-composite action is to determine the corresponding moment of inertia that is later used in calculating the degree of composite action.

Mastali, Mohammad, Valente, Isabel B., Barros, Joaquim A. O. (2017).

Flexural performance of innovative hybrid sandwich panels with special focus on the shear connection behaviour.

Paper submitted to Composite Structures, Elsevier, ISSN 0263-8223. 
Three different material models were introduced to model DHCC layer, polyurethane foam cores, and orthotropic GFRP material. To model the DHCC behavior, a plastic damage model was used. The model simulates the material nonlinearity from tensile cracking and plastic deformability in compression. The stress-strain behavior in uniaxial tension was simulated by the diagram represented in Fig. 4b, which has best fitted the experimental results. Additionally, elastic modulus and Poisson's ratio were considered equal to $10.00 \mathrm{GPa}$ and 0.20 , respectively. A linear behavior was adopted for simulating DHCC layer in compression. The stress-strain behavior in uniaxial compression was simulated by the diagram represented in Fig. 4c.

A crushable foam plasticity model with volumetric hardening and strain-rate sensitivity was used to simulate foam core behavior [15]. In this model, a uniaxial compressive elastic-plastic stressstrain relationship was adopted, which was defined by an elastic modulus and Poisson's ratio of $5.83 \mathrm{MPa}$ and 0.183 , respectively. In the adopted uniaxial compressive elastic-plastic stressstrain relationship for modeling foam cores, this material indicated an almost linear behavior up to an average compressive stress of $0.18 \mathrm{MPa}$, then followed by an almost perfectly plastic behavior up to an axial strain of about 0.3 .

In order to introduce orthotropic GFRP material, linear elasticity is defined by specifying the Engineering constants in FEM software. Engineering constants are used to define the elastic properties of GFRP materials in different directions [17].

The GFRP materials were considered orthotropic, with linear elasticity. Their compliance matrix is indicated in equation (5), defined by engineering constants are used in the three principal material directions, namely: $E_{1}, E_{2}, E_{3}$ (elasticity moduli); $v_{12}, v_{13}, v_{23}$ (Poisson's ratios); and $G_{12}$, $\mathrm{G}_{13}$, and $\mathrm{G}_{23}$ (shear modules).

$$
\left[\begin{array}{l}
\varepsilon_{1} \\
\varepsilon_{2} \\
\varepsilon_{3} \\
\gamma_{4} \\
\gamma_{5} \\
\gamma_{6}
\end{array}\right]=\left[\begin{array}{cccccc}
\frac{1}{E_{1}} & \frac{-v_{21}}{E_{2}} & \frac{-v_{31}}{E_{3}} & 0 & 0 & 0 \\
\frac{-v_{12}}{E_{1}} & \frac{1}{E_{2}} & \frac{-v_{32}}{E_{3}} & 0 & 0 & 0 \\
\frac{-v_{13}}{E_{1}} & \frac{-v_{23}}{E_{2}} & \frac{1}{E_{3}} & 0 & 0 & 0 \\
0 & 0 & 0 & \frac{1}{\mathrm{G}_{12}} & 0 & 0 \\
0 & 0 & 0 & 0 & \frac{1}{\mathrm{G}_{13}} & 0 \\
0 & 0 & 0 & 0 & 0 & \frac{1}{\mathrm{G}_{23}}
\end{array}\right]\left[\begin{array}{c}
\sigma_{11} \\
\sigma_{22} \\
\sigma_{33} \\
\sigma_{12} \\
\sigma_{13} \\
\sigma_{23}
\end{array}\right]
$$

Mastali, Mohammad, Valente, Isabel B., Barros, Joaquim A. O. (2017).

Flexural performance of innovative hybrid sandwich panels with special focus on the shear connection behaviour.

Paper submitted to Composite Structures, Elsevier, ISSN 0263-8223. 
The values adopted for engineering constants were determined from experimental tests, while the remaining ones were obtained from [20], which are indicated in Table 8.

Table 8. Properties considered for GFRP materials [20]

\begin{tabular}{c|c|c|c|c}
\hline $\begin{array}{c}\text { GFRP } \\
\text { material }\end{array}$ & $v_{12}$ & $\begin{array}{c}\text { In-plane } \\
\text { shear } \\
\text { modulus } \\
{[\mathrm{GPa}]}\end{array}$ & $\begin{array}{c}\text { In-plane } \\
\text { shear } \\
\text { strength } \\
{[\mathrm{MPa}]}\end{array}$ & $\begin{array}{c}\text { Compressive } \\
\text { strength at } \\
\mathbf{\mathbf { 4 4 5 }} \\
{[\mathrm{MPa}]}\end{array}$ \\
\hline Ribs & 0.53 & 8 & 100 & 90 \\
\hline Skin & 0.25 & 4 & ---- & ---- \\
\hline
\end{tabular}

Four-node tetrahedral elements were used to model the DHCC materials (Fig.17a). The simplest three-dimensional solid element available in the finite element analyst is the 4-node constant strain tetrahedral element [16]. This element is used abundantly in practice, as the analyst is able to mesh almost any volume regardless of its complexity. In the GFRP shear connector region, higher mesh refinement was adopted to better capture the stress field. GFRP rib and skin were simulated using 4-node constant strain tetrahedral elements, while 6-node linear triangular prism elements used to simulate the foam cores (Fig.17a). Using different elements can be justified by different geometry of slab's components. As the hybrid slabs had double symmetry, only one quarter of the specimen was modeled (Fig.17a) to decrease computing time.

The DHCC layer, GFRP rib, GFRP skin, and foam cores in Slab 1 were respectively modeled by 16011, 4652, 8212, and 20272 elements, while in Slab 2 these elements were modeled with 17763, 3999, 7788, and 15120 elements, respectively. Additionally, the boundary conditions used in the numerical simulations are illustrated in Fig.17b. The displacement in the X-axis is restricted on one surface of a quarter of slab and the displacement in direction of Z-axis is restricted on the other surface. Moreover, Fig. 17b illustrates the support condition, where diamond markers indicate the points with null displacement in the vertical direction (Y). Slabs were numerically simulated and loaded under FPB conditions, considering both fully-composite action and noncomposite action between DHCC layer and GFRP ribs and skin. In order to obtain the flexural stiffness in the hybrid slabs, perfect bond was assumed adequate to model the contact between slab's component of hybrid slabs, while for hybrid slabs with non-composite action, no bond was assumed to model the contact between slab's components of hybrid slabs and as each slab's component behaves independently. Non-composite action in the hybrid slabs can be described as degree of composite action equal to $0 \%$, while full composite slabs have a degree of composite action of $100 \%$, which act as a single unit in bending.

Mastali, Mohammad, Valente, Isabel B., Barros, Joaquim A. O. (2017).

Flexural performance of innovative hybrid sandwich panels with special focus on the shear connection behaviour.

Paper submitted to Composite Structures, Elsevier, ISSN 0263-8223. 
The results obtained in experimental tests and in numerical simulations are indicated in Table 9. Considering equation (2), the flexural stiffness (EI) values of the hybrid slabs were computed and listed in Table 9.
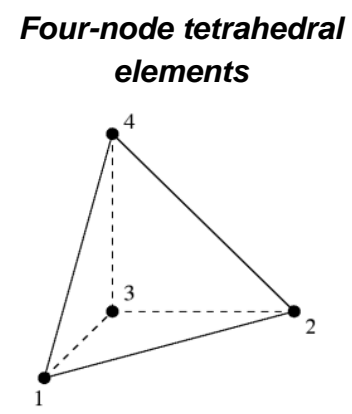

Six-node linear triangularprism elements

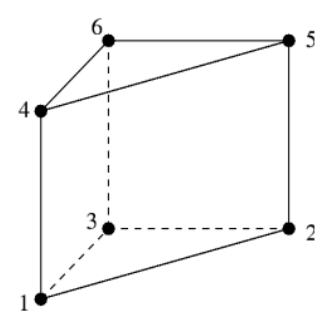

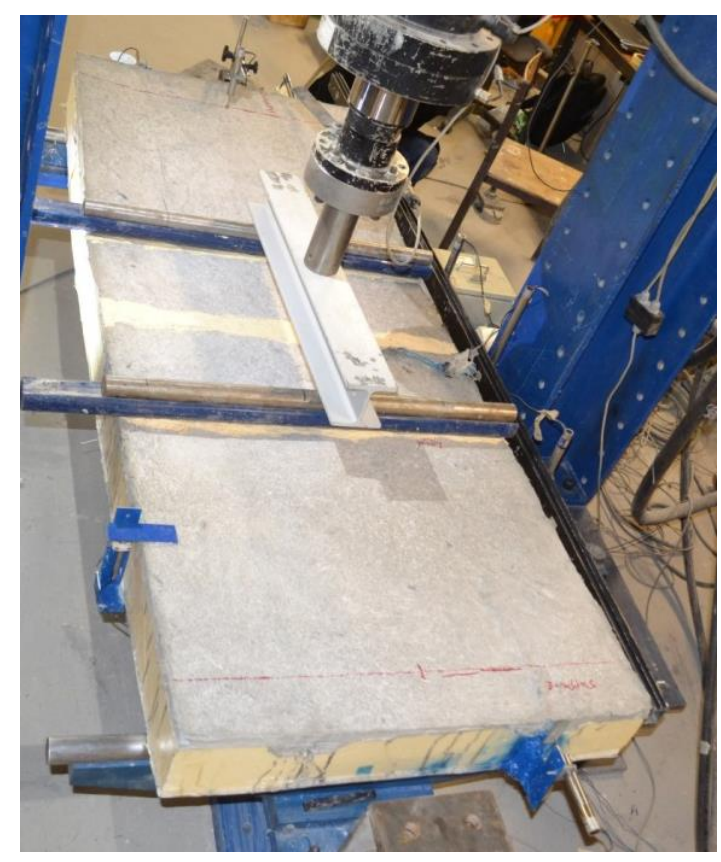

a)

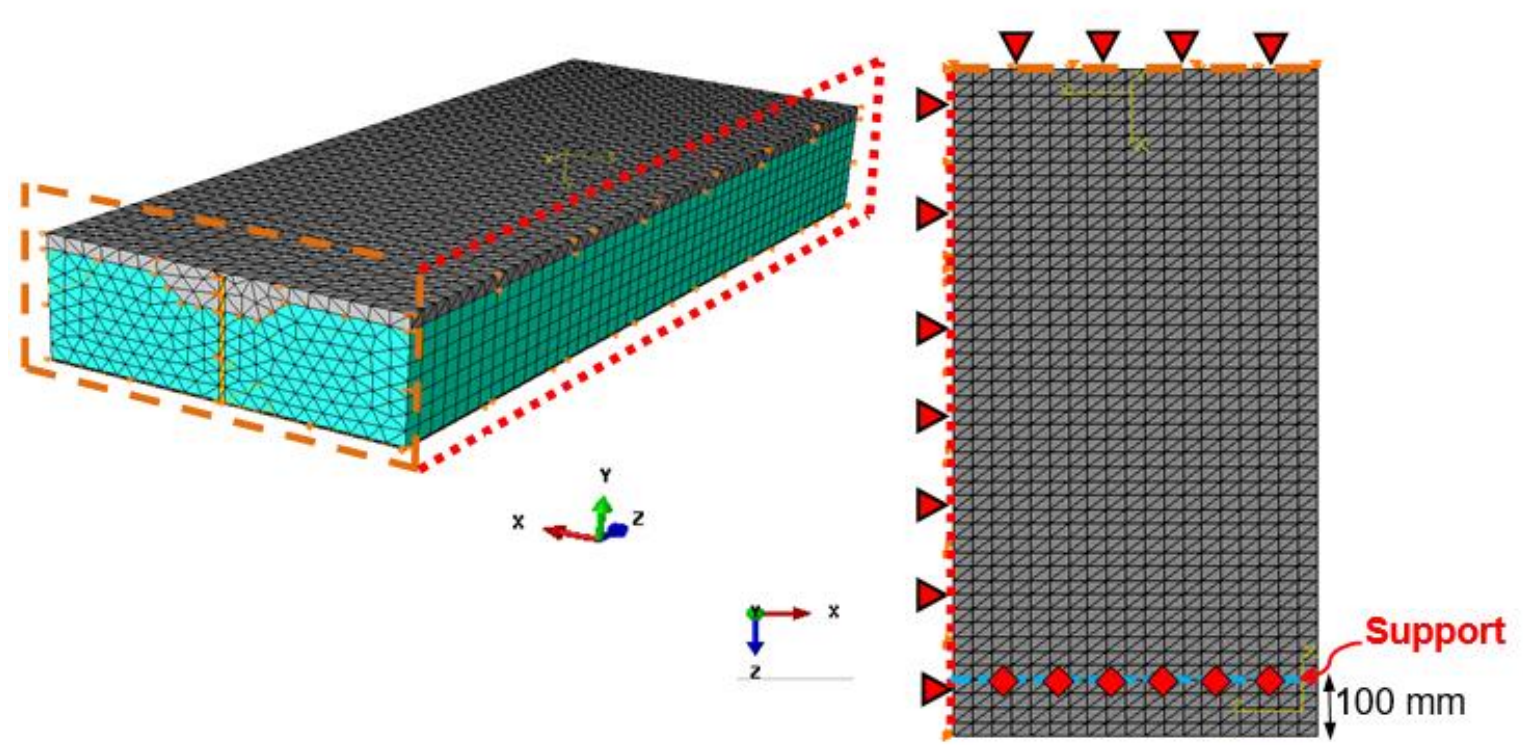

b)

Fig 17. a) Model of one quarter of the slabs and used elements; b) Boundary conditions

Mastali, Mohammad, Valente, Isabel B., Barros, Joaquim A. O. (2017).

Flexural performance of innovative hybrid sandwich panels with special focus on the shear connection behaviour.

Paper submitted to Composite Structures, Elsevier, ISSN 0263-8223. 
Using the values of flexural stiffness presented in Table 9 and applying equation (4), the degree of composite action for the Type 1 slabs with perforated and indented shear connectors were computed as $87 \%$ and $99 \%$, respectively. Moreover, the degree of composite action in Type 2 slabs with perforated and indented shear connectors were calculated as $94 \%$ and $72 \%$, respectively.

Table 9. Flexural stiffness (EI) of hybrid slabs

\begin{tabular}{|c|c|c|c|c|c|c|}
\hline \multirow[t]{2}{*}{ Slab type } & \multirow[t]{2}{*}{$\begin{array}{c}\text { Shear } \\
\text { connectors }\end{array}$} & \multirow{2}{*}{$\begin{array}{c}(\text { El })_{\text {Exp }} \\
\text { Experimental } \\
\left(\mathrm{KN} \cdot \mathrm{m}^{2}\right)\end{array}$} & \multicolumn{2}{|c|}{$\begin{array}{l}(E I)_{r c} \quad(E I)_{n c} \\
\text { Numerical }\end{array}$} & \multirow[t]{2}{*}{$(E I)_{E x p} /(E I)_{f c}$} & \multirow{2}{*}{$\begin{array}{c}\text { Degree of } \\
\text { composite action } \\
\text { (\%) }\end{array}$} \\
\hline & & & $\left(\mathrm{KN} . \mathrm{m}^{2}\right)$ & $\left(\mathrm{KN} \cdot \mathrm{m}^{2}\right)$ & & \\
\hline \multirow{2}{*}{ Type 1} & Perforated & 3365 & \multirow{2}{*}{3618} & \multirow{2}{*}{1727} & 0.94 & 87 \\
\hline & Indented & 3600 & & & 0.99 & 99 \\
\hline \multirow{2}{*}{ Type 2} & Perforated & 2376 & \multirow{2}{*}{2475} & \multirow{2}{*}{985} & 0.96 & 94 \\
\hline & Indented & 2044 & & & 0.82 & 72 \\
\hline
\end{tabular}

\section{Conclusions}

Providing effective shear connection between the GFRP ribs and the DHCC layer leads to obtain an increase of load capacity and a larger deflection in hybrid slabs. Therefore, within the scope of this paper, hybrid slabs using two types of shear connectors, including indented shear connectors, were built and experimentally tested. Then, the results obtained in the experimental tests performed in this study were used to implement a comparative study with hybrid slabs having perforated shear connectors. Both indented and perforated shear connectors provide an effective connection between DHCC layer and GFRP ribs. A simple, but efficient technology was adopted by executing holes of small diameter at the top zone of the GFRP embedded in the DHCC layer. The flexural performance of the hybrid sandwich slabs was assessed with experimental four point bending tests, and from the results obtained, the following relevant observations can be pointed out:

1) The use of different shear connectors at the ribs/DHCC connection has influence on peak load, deflection corresponding to peak load, residual load carrying capacity, and degree of composite action.

2) Using indented or perforated shear connectors in the hybrid slabs has no significant effect on the damage sequences.

Mastali, Mohammad, Valente, Isabel B., Barros, Joaquim A. O. (2017).

Flexural performance of innovative hybrid sandwich panels with special focus on the shear connection behaviour.

Paper submitted to Composite Structures, Elsevier, ISSN 0263-8223. 
3) Using indented shear connectors for type 1 slab provides about $14 \%$ higher degree of composite action in term of initial stiffness than using perforated shear connectors. For type 2 slab, using perforated shear connectors leads to about 30\% higher degree of composite action.

4) Regardless of the shear connector type, the maximum strain levels in the GFRP ribs and skin were much lower than the ultimate strain registered on the tensile tests carried out with coupons.

5) Load carrying capacity of hybrid slabs is mainly governed by the stiffness provided in the connection between GFRP ribs and DHCC layer.

6) Regardless of the shear connector type, the tested slabs presented an almost linear force versus mid-span response up to peak load, followed by a smooth softening structural behavior. These hybrid slabs proved to be a lightweight structural system with high load carrying capacity and considerable stiffness.

\section{Acknowledgements}

The study presented in this paper is a part of the research project "RehabGFRP - Rehabilitation of Building Floors with Lightweight High Performance GFRP Sandwich Panels", with reference number of PTDC/ECM/113041/2009. Furthermore, the authors honestly appreciate the collaboration of the following labs: Civitest for developing DHCC materials (Eng. Delfina Gonçalves), PIEP for conducting VARTM process (Eng. Luis Oliveira) and Department of Civil Engineering of Minho University to perform the tests (Mr. Antonio Matos and Eng. Marco Jorge).

\section{References}

1. J.R. Correia, M. Garrido, J.A. Gonilha, F.A. Branco, L.G. Reis, 2012, "GFRP sandwich panels with PU foam and PP honeycomb cores for civil engineering structural applications: Effects of introducing strengthening ribs", International Journal of Structural Integrity, Vol. 3, pp: 127 147.

2. T. M. Norton, 2004, "3D Orthogonal Woven Glass Fiber Reinforced Polymeric Bridge Deck: Fabrication and Experimental Investigation", Master thesis, North Carolina State University, USA.

Mastali, Mohammad, Valente, Isabel B., Barros, Joaquim A. O. (2017).

Flexural performance of innovative hybrid sandwich panels with special focus on the shear connection behaviour.

Paper submitted to Composite Structures, Elsevier, ISSN 0263-8223. 
3. M. Mastali, I.B. Valente, J.A.O. Barros, 2013, "New composite slab system for structural rehabilitation of traditional buildings", 11th International symposium on fiber reinforced polymers for reinforced concrete structures (FRPRCS-11), Guimarães, Portugal.

4. M.J. Charles, S. Tarek, S.H. Rizkalla, 2007, "Behavior of Three-Dimensionally Woven Glass Fiber Reinforced Polymeric Bridge Deck", Composites Research Journal, Vol. 1, pp: 27-42.

5. M. Mastali, I.B. Valente, J.A.O. Barros, D. Gonçalves, 2015, "Development of innovative hybrid sandwich panel slabs: Experimental results", Journal of Composite Structures, Vol. 133, pp: 476-498.

6. A.M. Brandt, 2008, "Fibre reinforced cement-based (FRC) composites after over 40 years of development in building and civil engineering", Journal of Composite Structures, Vol. 86, pp: 3-9.

7. A.E. Naaman, H.W. Reinhardt, 2006, "Proposed classification of HPFRC composites on their tensile response". Journal of Materials and Structures. Vol.39, pp: 547-555.

8. ASTM D3039/D3039-93, 2000. Standard test method for tensile properties of polymer matrix composite materials.

9. ASTM C365-03, 2004. Standard test method for flat wise compressive strength of sandwich cores.

10. R. Lameiras, J.A.O. Barros, I.B. Valente, Miguel A.D. Azenha, 2013, "Development of sandwich panels combining fiber reinforced concrete layers and fiber reinforced polymer connectors. Part I: Conception and pull-out tests", Journal of Composite Structures, Vol. 105, pp: 446-459.

11. M. Mastali M., I.B. Valente, J.A.O. Barros, 2016, "Development of innovative hybrid sandwich panel slabs: Advanced numerical simulations and parametric studies", Journal of Composite Structures, Vol. 152, pp: 362-381.

12. S. Pessiki, A. Mlynarczyk, 2003, "Experimental evaluation of the composite behavior of precast concrete sandwich wall panels", Journal of $\mathrm{PCl}$, Vol. 48,pp: 54-71.

13. ABAQUS Theory Manual and Users Manuals. Version 6.9-3, 2010, Hibbitt, Karlsson and Sorensen, Inc., USA.

14. http://www.fisipe.pt/catalogo/listaprodutos.php?cat=2\&sessao=1

(Date accessed: $\underline{01.08 .2016)}$

15. X. Wei, Phuong Tran, A. Vaucorbeil, R. Ramaswamy, F. Latourte, Horacio D. Espinosa, 2013, "Three-dimensional numerical modeling of composite panels subjected to underwater blast", Journal of the Mechanics and Physics of Solids, Vol. 61, pp: 1319-1336.

Mastali, Mohammad, Valente, Isabel B., Barros, Joaquim A. O. (2017).

Flexural performance of innovative hybrid sandwich panels with special focus on the shear connection behaviour.

Paper submitted to Composite Structures, Elsevier, ISSN 0263-8223. 
16. D. J. Payen, K. Bathe, 2011, "Improved stresses for the 4-node tetrahedral element”, Journal of Computers and Structures, Vol. 89, pp: 1265-1273.

17. G. Venu Gopala Rao, P. Mahajan, N. Bhatnagar, 2007, "Micro-mechanical modeling of machining of FRP composites - Cutting force analysis", Journal of Composites Science and Technology, Vol. 67, pp: 579-593.

18. American Society for Testing and Materials (ASTM) C39, Standard Test Method for Compressive Strength of Cylindrical Concrete Specimens, 2001.

19. A. Abrishambaf, V. Cunha, Joaquim A.O. Barros, 2016, "The influence of fibre orientation on the post-cracking tensile behaviour of steel fibre reinforced self-compacting concrete", Fracture and Structural Integrity Journal, Vol. 31, pp: 38-53, 10.3221/IGF-ESIS.31.04 http://hdl.handle.net/1822/32127.

20. Selcom multiaxial technology company, Biaxial products. http://www.multiaxialfabricselcom.com/en/Products/ (Date accessed: 01.08.2016).

21. A.E. Naaman, H.W. Reinhard, 2005, "Proposed classification of HPFRC composites based on their tensile response", Proceedings 3rd international Conference on Construction materials: Performance, Innovations and Structural Implications (ConMat'05) and Mindess Symposium, p. 458, Eds: N. Banthia, A. B., T. Uomoto \& Shah, S., University of British Columbia, Vancouver, Canada.

22. C. Faella, E. Martinelli, E. Nigro, 2010, "Steel-concrete composite beams in partial interaction: Closed-form "exact" expression of the stiffness matrix and the vector of equivalent nodal forces", Engineering Structures, Vol. 32, pp: 2744-2754.

Mastali, Mohammad, Valente, Isabel B., Barros, Joaquim A. O. (2017).

Flexural performance of innovative hybrid sandwich panels with special focus on the shear connection behaviour.

Paper submitted to Composite Structures, Elsevier, ISSN 0263-8223. 